\title{
A influência dos pressupostos metodológicos na condução de pesquisas científicas em gestão de riscos ambientais
}

Methodological assumptions influence on environmental risk management scientific research conduction

\author{
Fabrício Kurman Merlin', Solange Maria Loureiro², Vera Lúcia Duarte do Valle Pereira ${ }^{3}$ \\ 'Universidade Tecnológica Federal do Paraná, PR, Brasil \\ 2Instituto Federal de Santa Catarina, SC, Brasil \\ ${ }^{3}$ Universidade Federal de Santa Catarina, SC, Brasil
}

\section{Resumo}

O presente artigo tem por finalidade discutir sobre a necessidade da devida compreensão e domínio, por parte dos pesquisadores, sobre as bases filosóficas dominantes, as lógicas de racionalidade (métodos) e as caracterizações utilizadas na condução de pesquisas científicas, bem como a importância em se considerar a complementaridade entre essas bases, na abordagem dos fenômenos, para a construção do conhecimento científico. Para tal, apresenta a análise de um conjunto de artigos selecionados, na área da gestão de riscos ambientais, utilizando-se da referência de Pacheco Júnior, Pereira e Pereira Filho (2007), na evidenciação da influência dos pressupostos metodológicos no desenvolvimento de pesquisas científicas.

Palavras-chave: Ciência; metodologia; método; gestão ambiental; riscos.

\begin{abstract}
This article aims to discuss the need for proper understanding and mastery on the part of the researchers on the dominant philosophical underpinnings, logics of rationality (methods) and characterizations used in conducting scientific research, and the importance in considering the complementarity between these underpinnings, on the approach of the phenomena, for the construction of scientific knowledge. For such, it presents the analysis of a set of selected papers in the environmental risk management area, using the reference of Pacheco Junior, Pereira and Pereira Filho (2007), on the disclosure of the influence of methodological assumptions in the development of scientific research.
\end{abstract}

Keywords: Science; methodology; method; environmental management; risks. 


\section{INTRODUÇÃO}

Em suas páginas introdutórias, Pacheco Junior, Pereira e Pereira Filho (2007), referenciam à obra de Hunter (2004), que descreve sobre quatro estágios da maturação do indivíduo na aquisição de novas habilidades, em termos da propensão à ação e a ação expressa, sendo elas: 1) Inconsciência e inabilidade; 2) Consciência e inabilidade; 3) Consciência e habilidade; e, 4) Inconsciência e habilidade. Esses estágios de maturação estão presentes no processo de aprendizagem do ser humano, inclusive na pesquisa científica.

Nesta, em específico, o primeiro estágio da maturidade é característico de indivíduos que nada sabem sobre a pesquisa científica e, em razão disso, não desenvolvem atividades nesta área. No segundo estágio, o indivíduo aprende sobre o assunto, porém, como está numa fase de aprendizagem e desenvolve novos conceitos, acaba não desenvolvendo habilmente atividades pelo fato da prática de investigação não ter se tornado um hábito. No terceiro estágio, o indivíduo tem consciência sobre o que seja a pesquisa científica e demonstra habilidade para o desenvolvimento de investigações nesta área que, se for constante, acaba se tornando um hábito. E, na quarta, por se tornar frequente a prática de desenvolvimento de investigações, o indivíduo internaliza o aprendizado e, assim, acaba se tornando um hábito, agindo por automatismo (PACHECO JUNIOR, PEREIRA E PEREIRA FILHO, 2007, p.1-2).

O pesquisador iniciante, que se enquadraria nos dois primeiros estágios da maturação, no que se refere às investigações, necessita de conteúdo técnico-teórico para que lhe seja possível executar práticas consistentes e credíveis no âmbito científico. Esse requisito será obtido, em termos gerais, se houver, por parte do indivíduo, uma predisposição para desenvolver a habilidade de investigação. Como a ciência se pauta no formalismo e no rigor metodológico, a aprendizagem sobre esses aspectos deve ser atendida. Logo, é importante a consciência de suas carências, limitações e complementaridades.

O pesquisador experiente possui conteúdo técnico-teórico suficiente que lhe permita desenvolver atividades sob a ótica científica, estando, portanto, nas duas últimas categorias referidas. Esse indivíduo tem maturidade, porque as suas habilidades em investigações científicas apresentam consistência e são consideradas credíveis, em razão de ser a execução da pesquisa pautada pelo rigor metodológico e a apresentação dos seus resultados seguir um formalismo inconteste. É detentor do conhecimento desses princípios que regem os trabalhos científicos e, aparentemente, não possui sérias indagações no desenvolvimento de suas atividades.

No grupo de pesquisadores nos dois primeiros estágios, há os que nada sabem e os que sabem alguma coisa. No grupo dos dois últimos estágios, estão os que vislumbram um horizonte claro de suas atividades, com pouco ou quase nenhuma complicação que lhes impeça de utilizar bem os aspectos metodológicos em pesquisas científicas. Ultrapassar a barreira entre o pesquisador iniciante e o experiente exige que os aspectos metodológicos, utilizados em pesquisas científicas, sejam desvendados pelo iniciante. Contudo, para Pacheco Junior, Pereira e Pereira Filho (2007, p.3) está não é uma tarefa fácil,

pois há distintas correntes científicas com discussões filosóficas e metodológicas que se perdem em meio das infinitas publicações técnicas e, sob o ponto de vista da educação, nem sempre os pesquisadores experientes têm tempo e paciência para ensinar os novatos, especialmente que são categorizados como inconscientes e hábeis, em razão dos conceitos estarem internalizados.

A percepção que se tem, na área de pesquisa da gestão de riscos ambientais, não é diferente. São diversos autores que abordam o assunto sob diferentes perspectivas: na participação de diferentes stakeholders para as tomadas de decisões (Beierle, 2002; El-Zein et al., 2006; Lacoursiere, 2006; Carey et al., 2007; Earle e Siegrist, 2008; Roca, Gamboa e Tàbara, 2008); questões referentes à saúde humana (Romerio, 2002; Brugge et al.; 2003; Bryant e Abkowitz, 2007; Nadal et al., 2008; Bruhn e Frick, 2011); no desenvolvimento do ferramental de apoio à decisão (Fedra e Winkelbauer, 2002; Pollard et al., 2004; Van Der Sluijs et al., 2005; Roca, Gamboa e Tàbara, 2008; Fanghua e Guanchun, 2010; Qin, 2012; Tan, Huang e Cai, 2012); no monitoramento e controle dos recursos hídricos (Yuan et al., 2007; Paleologos, 2008; Fanghua e Guanchun, 2010), dentre outras. As diferentes perspectivas de abordagens estão subordinadas às visões de mundo do pesquisador, bem como ao contexto institucional ao qual 
o mesmo pertence. É por meio dessa visão de mundo que a construção do conhecimento científico terá a sua continuidade, sendo influenciada por elementos tais como: o fenômeno a ser investigado; sua experiência ou habilidade na condução de pesquisas; seus conhecimentos prévios; suas crenças e valores, além daquelas da instituição a qual pertence e provê os recursos para viabilizar suas investigações; os vieses da própria área de pesquisa etc.

Diante dessa complexidade imposta, tal como esse termo é compreendido e explorado por Morin (2011), a qual o pesquisador está exposto, os autores deste artigo propõem uma discussão sobre a influência dos pressupostos metodológicos na condução de pesquisas científicas. Atentando-se, inicialmente, sobre as bases filosóficas dominantes, as lógicas de racionalidade (métodos) e as caracterizações utilizadas na condução dessas pesquisas. Além disso, este artigo busca lançar um olhar sobre a importância em se considerar a complementaridade entre essas bases, na abordagem dos fenômenos, para a construção do conhecimento científico. Assim, apresenta a análise de um portfólio composto por 37 artigos selecionados, na área da gestão de riscos ambientais, utilizando-se da referência de Pacheco Júnior, Pereira e Pereira Filho (2007), na evidenciação da influência desses pressupostos metodológicos, no desenvolvimento de pesquisas científicas.

\section{REFERENCIAL TEÓRICO}

\section{I O CONHECIMENTO CIENTÍFICO}

A ciência, nos moldes atuais, praticamente surgiu durante o Renascimento, a partir do século XV com as contribuições, dentre outras personalidades, de Galileu Galilei (1464-1542), Francis Bacon (1561-1626) e René Descartes (1596-1650), pela proposição de investigações a partir de um método de pesquisa (JAPIASSU, 2007; PACHECO JUNIOR, PEREIRA e PEREIRA FILHO, 2007). Enquanto Galilei advogou pelo empirismo, pautado na observação e apreensão dos fenômenos pelos sentidos, Bacon apregoou que a prática da experiência seria necessária para gerar 'leis gerais e universais'. Descartes, por sua vez, propôs a divisão do 'todo' em suas partes componentes, na busca do conhecimento, no que se referiria à matéria. Isso trouxe sérias implicações nas interpretações posteriores de suas obras, como a separação entre corpo e mente que levou a desconsiderar a subjetividade.

O conhecimento científico, por buscar explicações, desde os fenômenos naturais aos sociais, deve possuir uma característica factual e objetiva, ao invés de valorativa e subjetiva. Essas características permitem que os fenômenos possam ser explicados por métodos sistemáticos que podem ser verificados para validação. A partir dessas considerações, pode-se dizer que ciência seja

o conjunto de conhecimentos gerados a partir de hipóteses acerca de fenômenos, obtidos por meio de procedimentos sistemáticos, lógicos e racionais, e passíveis de verificação para comprovar a sua valia (PACHECO JUNIOR, PEREIRA e PEREIRA FILHO, 2007, p.8). dro 1):

Assim, o objeto da ciência é o conhecimento, que deve, dentre outras características, ser (Qua-

Quadro 1 - Características básicas do conhecimento científico.

\begin{tabular}{|c|l|}
\hline Característica & \multicolumn{1}{c|}{ Descrição } \\
\hline Factual & $\begin{array}{l}\text { Derivado de fenômenos reais, ou seja, de toda forma e existência que se manifesta } \\
\text { de algum modo. }\end{array}$ \\
\hline Sistemático & $\begin{array}{l}\text { Deve apresentar uma ordenação lógica de conhecimentos preexistentes, } \\
\text { formando um sistema de ideias (teoria), possibilitando mostrar o encadeamento } \\
\text { das ideias que levam ao novo conhecimento do fenômeno estudado. }\end{array}$ \\
\hline Verificável & $\begin{array}{l}\text { Deve haver a explicitação da sequência lógica do desenvolvimento do trabalho, } \\
\text { de modo a possibilitar a sua repetição e, assim, verificar o resultado da hipótese } \\
\text { do estudo do fenômeno. }\end{array}$ \\
\hline
\end{tabular}

continua... 
Quadro 1 - Continuação..

\begin{tabular}{|c|l|}
\hline Característica & \multicolumn{1}{|c|}{ Descrição } \\
\hline Contingente & $\begin{array}{l}\text { Dependente da situação em que o fenômeno é estudado. As hipóteses } \\
\text { ou proposições têm a sua veracidade ou falsidade conhecida através da } \\
\text { experimentação metódica e, deste modo, o contexto em que os resultados são } \\
\text { obtidos deve ser explicitado, para mostrá-lo e não originar dúvidas. }\end{array}$ \\
\hline Falível & $\begin{array}{l}\text { Não é considerado definitivo, nem absoluto ou final, em virtude de haver } \\
\text { contextos diferentes para um mesmo fenômeno, exceto nos casos em que a teoria } \\
\text { é comprovada para todos os contextos, gerando uma lei científica. }\end{array}$ \\
\hline $\begin{array}{c}\text { Aproximadamente } \\
\text { exato }\end{array}$ & $\begin{array}{l}\text { Que pode ser reformulado ou reavaliado, em razão de haver outros possíveis } \\
\text { caminhos para compreender um mesmo fenômeno, com o surgimento de } \\
\text { proposições alternativas e o desenvolvimento de novas técnicas, reduzindo os } \\
\text { vieses de análises. }\end{array}$ \\
\hline
\end{tabular}

Fonte: Pacheco Junior, Pereira e Pereira Filho (2007, p. 8-9).

Quadro 2 - Classificação da pesquisa quanto à abordagem ao objeto de estudo.

\begin{tabular}{|c|l|}
\hline Classificação & \multicolumn{1}{c|}{ Descrição } \\
\hline $\begin{array}{c}\text { Pesquisa } \\
\text { exploratória }\end{array}$ & $\begin{array}{l}\text { Constitui o primeiro estágio de uma pesquisa científica, uma vez que caracteriza, } \\
\text { classifica e define o problema. Em geral, trata-se de uma pesquisa em que não se } \\
\text { conhece muito bem o objeto de estudo e, para tal, torna-se necessário realizar uma } \\
\text { investigação inicial para que haja uma melhor compreensão do mesmo. }\end{array}$ \\
\hline $\begin{array}{c}\text { Pesquisa } \\
\text { teórica }\end{array}$ & $\begin{array}{l}\text { Baseia-se apenas no conhecimento existente, voltando-se para uma relação lógica } \\
\text { e avaliação sistemática dos construtos teóricos, deste modo, possibilitando ampliar } \\
\text { as generalizações, definir as leis científicas, estruturar os sistemas, definir modelos } \\
\text { teóricos e gerar novas hipóteses. É uma pesquisa que, dado o caráter de se basear } \\
\text { somente no conhecimento existente, reconstruindo-o, não é necessariamente aplicável, } \\
\text { à realidade, porém, cria condições para que seja verificado, em razão de haver } \\
\text { necessidade de rigor conceitual e da habilidade à análise dos elementos das diversas } \\
\text { teorias, em forma lógica e sistemática. }\end{array}$ \\
\hline $\begin{array}{c}\text { Pesquisa } \\
\text { aplicada }\end{array}$ & $\begin{array}{l}\text { Busca a aplicação do seu desenvolvimento teórico no contexto do objeto de estudo e, } \\
\text { para tanto, utiliza ferramental metodológico predefinido e reconhecido como válido } \\
\text { pela ciência, ou, seguindo o rigor metodológico. }\end{array}$ \\
\hline
\end{tabular}

Fonte: Pacheco Junior, Pereira e Pereira Filho (2007, p. 9-10).

\subsection{As BASES FILOSÓFICAS}

Richardson et al. (1999) evidenciam serem três as principais bases filosóficas que norteiam a pesquisa científica: o positivismo lógico, o estruturalismo e o materialismo dialético.

Ainda que a filosofia abranja um espectro muito maior do que essas três bases filosóficas e com disparidades de enfoques (historicistas, vitalistas, existencialistas e personalistas, por exemplo), sob a ótica científica, apenas elas parecem suportar os critérios de proporcionar estudo factual e objetivo na obtenção de conhecimento, razão pela qual nesta obra se assume como um referencial de definição filosófica (PACHECO JÚNIOR, PEREIRA e PEREIRA FILHO, 2007, p.43). 
$\mathrm{Na}$ atualidade, podem-se considerar essas bases como norteadoras de pesquisa, em abordagens sistêmicas. Contudo, com denominação diferenciada para duas destas três correntes filosóficas, são elas: positivismo, estruturalismo e dialética. Richardson et al. (1999) advogam que as classificações diferenciadas, adotadas por diversos autores, em face de reações contrárias, são passíveis de serem enquadradas neste espectro de princípios filosóficos.

\subsection{Positivismo}

Por influência das ideias do empirismo e difusão da sociedade industrial na Europa do século XVII e XVIII, Isidore Auguste Marie François Xavier Comte (1798-1857) formaliza as ideias positivistas, aplicadas na ciência, para viabilizar, também, a organização racional da sociedade, em oposição à filosofia meramente especulativa (GOULART, 2007; PACHECO JUNIOR, PEREIRA e PEREIRA FILHO, 2007). Tais ideias propunham que os fenômenos deveriam ser explicados por teorias que os sustentassem e, assim, seria necessário descrevê-los e conhecê-los através da observação dos fatos único modo certo de conhecer a realidade. Desta forma, não é o sujeito cognoscente que serve de referência na apreensão do conhecimento, mas a objetividade da observação é o que sustenta o processo, retirando-se, assim, a subjetividade no processo de gerar conhecimento. Isso implica na neutralidade científica, para a formulação de leis naturais que regem os fenômenos.

O positivismo influenciou historicamente as pesquisas, porém, sofreu (e ainda sofre) pesadas críticas, pelo fato de ser acusado de reducionista, ou seja, preocupar-se tão somente das manifestações imediatas e concretas dos fenômenos, sem considerar a subjetividade, bem como as amplas relações entre os elementos dos fenômenos, além daquelas entre os fenômenos. Contudo, o fundamento positivista de Comte ainda persiste como filosofia, uma vez que a geração de conhecimento à formação de teorias parte do princípio da experiência empírica, com proposições factuais. Logo, sob uma ótica sistêmica (BERTALLANFY, 1975), a concepção fundamental do positivismo seria a de gerar o conhecimento das leis que regem os fenômenos, priorizando-se apenas entradas (causas) e saídas (efeitos), para explicá-lo em termos de lógica e racionalidade, em um contexto estrito. Restringem-se as influências ambientais sobre o sistema e as próprias relações entre os elementos que compõem o processo, que caracterizaria o fenômeno (Figura 1).

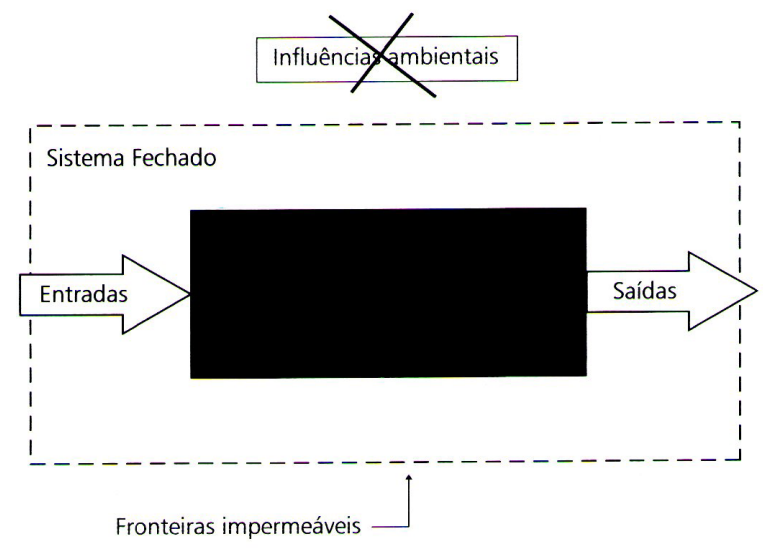

Figura 1 - Concepção sistêmica do positivismo.

Fonte: Pacheco Junior, Pereira e Pereira Filho (2007, p. 46).

Pode-se dizer, então, que o positivismo busca estudar a relação objetiva entre variáveis em estudo (entradas e saídas), através da experiência (único critério da verdade), mostrando a valia ou não de interdependência, por exemplo, variação de temperatura versus dilatação de uma barra de ferro, negligenciando os elementos que sustentam o fenômeno.

\subsubsection{Estruturalismo}

O estruturalismo surgiu de estudos na área da linguística, através da obra que compilou os trabalhos de Ferdinand de Saussure (1857-1913), por Charles Bally e Albert Sechehaye, publicada em 1915, com o título Cours de linguistique génerale. Saussure propôs que a linguagem seria formada por 
unidades ou elementos que formam estruturas subjacentes a qualquer idioma e a qualquer discurso, os quais somente podem ser definidos pelas relações de equivalência ou de oposição em relação aos demais elementos. Essas estruturas estão presentes em qualquer idioma e em qualquer discurso, fazendo assim, com que qualquer língua possa ser considerada como um sistema composta de estruturas interdependentes (THIRY-CHERQUES, 2006).

As premissas do estruturalismo permitiram a muitos vislumbrarem a abordagem como aplicável, o que se transformou numa grande influência nas pesquisas científicas, em diversas áreas sociais, tendo em vista o fato de o positivismo carecer de um referencial que buscasse melhor compreender a relação entre os elementos de um dado processo. Foi o que ocorreu, ainda no século XX, em estudos sociológicos, antropológicos e filosóficos, com foco nas questões relacionadas à linguagem, tal como a cultura, tratando os elementos de estudo como objetos simbólicos. Foi, também, essas premissas que possibilitaram a Claude Lévi-Strauss (1908-2009) construir uma base teórica para seus estudos antropológicos em que ele pudesse transpor a ponte entre o lógico e o empírico para explicar a diversidade do mundo e entender o espírito humano por meio da superação do contraditório entre a realidade observada e o que pode ser reunido, observado e transmitido acerca do objeto de estudo (THIRY-CHERQUES, 2006; PACHECO JUNIOR, PEREIRA e PEREIRA FILHO, 2007).

A ideia central do estruturalismo é a de que a estrutura é determinante na explicação dos objetos psicossociais. Para tanto, são consideradas as estruturas superficiais (observáveis diretamente) e as profundas (subjazem ao aparente e imediato). Para Thiry-Cherques (2006, p.142) por definição

a estrutura é um sistema relacional ou um conjunto de sistemas relacionais, tais como as relações de parentesco, os esquemas de controle de tráfego, os códigos de etiqueta, etc. Uma estrutura é um todo formado de fenômenos solidários. Cada um dos seus elementos depende dos outros e é determinado por sua relação com eles. A alteração, acréscimo ou supressão de um elemento implica acomodação e reajuste na posição dos demais. É preciso distinguir o conceito de estrutura do de sistema. [...] O sistema é um modelo dinâmico, descreve a ação de um conjunto de elementos funcionais (entrada, processo, saída, feedback, etc.). [...] a estrutura é um modelo explanatório abstrato, que descreve propriedades relacionais entre elementos.

O estruturalismo também passou a ser objeto de aplicação em outras áreas, como a biologia, a matemática e a engenharia, sempre reconhecendo e tratando as relações dos elementos fundamentais, dentro de uma estrutura sistêmica, valorizando o conhecimento do próprio processo na explicação da relação entre variáveis. Por exemplo, entender o porquê do comportamento de certo fenômeno, estabelecendo-se um modelo que poderá servir de referencial para casos similares.

O estruturalismo se constitui em uma base filosófica da ciência e, sob o ponto de vista sistêmico, seu objeto são as relações entre os elementos que compõem um processo na explicação dos fenômenos. Ou seja, para gerar conhecimento das causas (entradas) e efeitos (saídas) de um dado processo, é imprescindível conhecer essas relações (Figura 2).

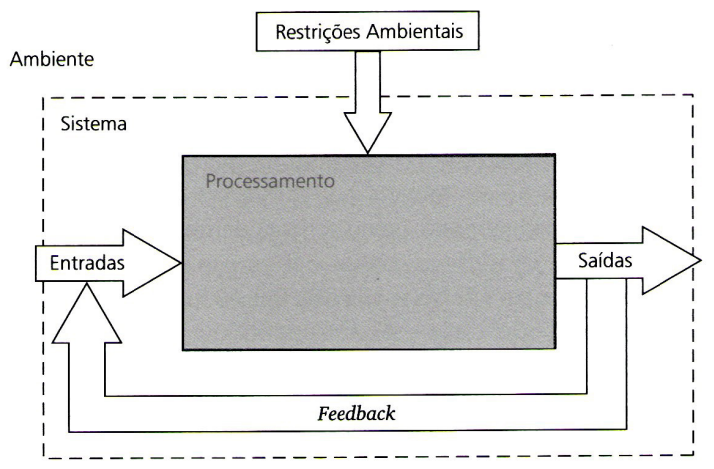

Figura 2 - Concepção sistêmica do estruturalismo.

Fonte: Pacheco Junior, Pereira e Pereira Filho (2007, p. 48).

Conforme referido por Richardson et al. (1999), o objeto de estudo deve obedecer aos critérios que caracterizam um sistema. Neste aspecto, reconhece-se que o fenômeno de estudo deva ser caracterizado 
em seus elementos fundamentais (entradas, processos, saídas, retroalimentação ou feedback, limites ou fronteiras e ambiente externo de influência) em suas relações que incluem, também, as influências ambientais preponderantes, bem como os componentes que o regem e no que for cabível, sendo estes:

Material (hardware): elementos de constituição física do processo;

Funcional (software): elementos de constituição funcional do processo;

Controle (orgware): elementos de reajuste funcional do processo; e,

Humana (humanware): elementos de operacionalização humana do processo

\subsubsection{Dialética}

A dialética, em seu conceito geral, remonta à Grécia antiga, onde os filósofos consideravam a essência da filosofia, e sua base se constituía em a negação da negação (PACHECO JUNIOR, PERERIA e PEREIRA FILHO, 2007). Tal concepção, para um pesquisador iniciante, aparentará ser algo estranho, especialmente pelo fato da cultura científica principiar, normalmente, pela simples concepção positivista de causa e efeito ou, quando muito, algo de desvendar a relação dos elementos de um processo, característica básica do estruturalismo.

Todavia, o que se deve compreender é que a dialética sempre esteve ligada à coerência, numa lógica de diálogo buscando um consenso entre dois discursos opostos. Com efeito, etimologicamente, esse termo deriva do grego dialetiké, com significado de debate, ensejando que o senso seja no sentido de haver o contraditório para se chegar ao consenso entre as partes. Tem, assim, como característica principal buscar entender a essência do objeto de estudo, partindo do pressuposto que para toda tese existe uma antítese (ou anti-tese) e, assim, buscar a síntese desses conhecimentos para a sua compreensão em termos de existência no Universo (PACHECO JUNIOR, PEREIRA e PEREIRA FILHO, 2007, p.49).

Pode-se dizer, então, que a dialética é uma forma de pensar em que há a necessidade de descrever e confrontar os opostos para se conhecer os fenômenos; porém, não de uma forma estática (MINAYO, 2010). Requer uma definição espacial e histórica dos contrários (e do próprio fenômeno para com outros), a fim de ser possível situá-los como reveladores do conhecimento (PACHECO JUNIOR, PEREIRA e PEREIRA FILHO, 2007; MINAYO, 2010).

Por exemplo, partindo-se do fato de que o estresse promove a ansiedade do indivíduo (tese) e, em contrapartida, de que esse também provoque a depressão (antítese), busca-se a síntese desses conhecimentos para conhecer o fenômeno estresse. Mas esta síntese deve levar em consideração os momentos em que ansiedade e depressão se manifestam em decorrência do estresse, pois ambas são causas naturais que ocorrem diferentemente nas pessoas (organismos biopsicosociais), e são influenciadas por fatores intra e extra-individual. Logo, tese e antítese devem ser confrontadas, para que se tenha uma síntese do fenômeno estresse, através da eliminação dos contraditórios, que não se sustentam na lógica da realidade (PACHECO JÚNIOR, PEREIRA e PEREIRA FILHO, 2007, p.50).

A dialética tem diversos momentos, surgindo diferentes correntes ao longo da história. Entretanto, pode-se dizer que, o que governa essa base filosófica é o conceito de coerência sistêmica na dinâmica histórica entre os opostos, independentemente do foco das linhas metodológicas (MINAYO, 2010).

À adoção da dialética em estudos científicos, o pesquisador deveria atentar para alguns requisitos básicos desta base filosófica, sendo (PACHECO JUNIOR, PEREIRA e PEREIRA FILHO, 2007; MINAYO, 2010):

A dialética requer que haja o contraditório e, assim, tese e antítese são essenciais;

No foco científico, tese e antítese são objetos históricos e, portanto, devem ser descritos em seus elementos fundamentais e estes em suas relações, para que se possa descrevê-los em um quadro realista; e,

O contraditório deve ser peça de análise, exigindo-se confrontar tese e antítese na busca de 
inconsistências técnicas e teóricas sem suporte lógico, bem como as conexões que devam dar origem à síntese que explica o fenômeno de estudo.

Numa abordagem sistêmica, a dialética não ficaria restrita e a um único objeto de estudo, mas sim de dois (PACHECO JÚNIOR, PEREIRA e PEREIRA FILHO, 2007). Isto significa, ao definir-se uma tese, poder-se-ia caracterizá-la com um sistema e, de igual modo, seria o caso da antítese. A confrontação desses sistemas daria, então, a possibilidade de encontrar as vinculações e as inconsistências entre os seus elementos, originando a síntese (Figura 3).

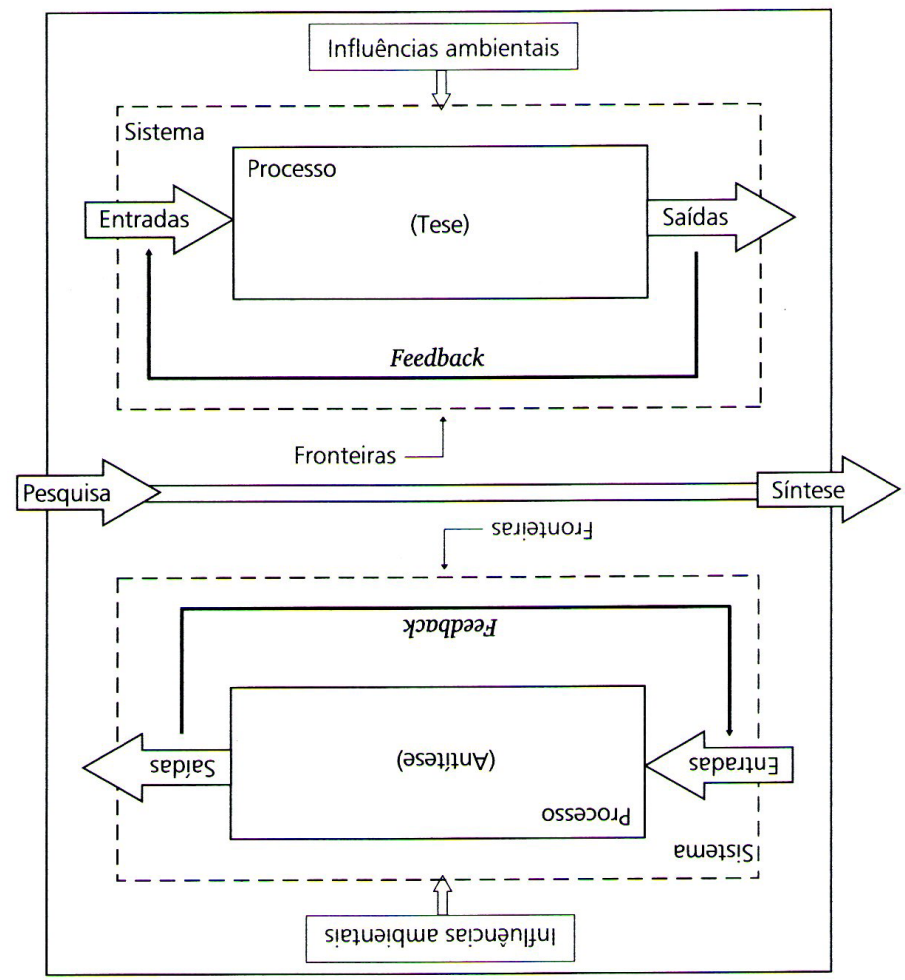

Figura 3 - Concepção sistêmica da dialética.

Fonte: Pacheco Junior, Pereira e Pereira Filho (2007, p. 52).

Ressalta-se que o foco sistêmico oportuniza melhor descrição de tese e antítese, visto que as influências ambientais devam ser consideradas, inclusive, preliminarmente, expondo as conexões entre ambas. É o caso do exemplo do estresse que pode ocasionar ansiedade e depressão, visto estas serem resultantes de condicionantes sobre o sistema fisiológico do indivíduo.

\subsection{As LÓGICAS DE RACIOCÍNIO}

Sob a ótica da abordagem sistêmica e nos fundamentos conceituais sobre ciência, as três bases filosóficas norteiam os princípios de pensamento do pesquisador, evidenciando que um mesmo objeto de pesquisa pode assumir trajetórias diferentes (PACHECO JUNIOR, PEREIRA e PEREIRA FILHO, 2007). Então, em termos de raciocínio lógico, uma pesquisa pode diferir de outra para um mesmo fenômeno, caracterizando que os caminhos que levam ao conhecimento científico possam ser classificados segundo uma linha de pensamento (MINAYO, 2010). Estes caminhos dependem, essencialmente, do escopo do pesquisador, o que leva a ponderar acerca dos resultados práticos de uma pesquisa na geração do conhecimento científico para um dado objeto de estudo (PACHECO JUNIOR, PEREIRA e PEREIRA FILHO, 2007):

O conhecimento sobre o objeto inexiste ou sofre restrição à sua plena aceitação por carência de informações; 
O conhecimento sobre o objeto existe e é aceito sem expressivas restrições; e,

O conhecimento do objeto existe, porém, com significativas contestações.

Quando não há conhecimento do objeto de estudo, ou que esse seja de pouca expressividade, fica evidente que o caminho a ser seguido é o de desvendá-lo, o que caracteriza uma pesquisa eminentemente exploratória. Neste caso, por carência de conhecimento, este deve ser gerado a partir de casos particulares e são duas as possibilidades de fazê-lo (PACHECO JUNIOR, PEREIRA e PEREIRA FILHO, 2007):

1 Descrevendo o objeto, sem a oportunidade de relacionar outros que poderia resultar em associações com casos semelhantes e, desse modo, generalizar os resultados; e,

2 Verificar, através do raciocínio lógico, as respectivas associações entre os dados dos diversos objetos semelhantes estudados. Caso elas existam, generalizar os resultados.

No primeiro caso, normalmente ocorrendo por questões relativas à falta de recursos ou tempo, o caminho é apenas o da descrição do objeto de estudo, o que não pode ser descartado como um método de pesquisa, desde que os fundamentos científicos sejam respeitados, tendo em vista a geração de conhecimento e resultados passíveis de verificação (PACHECO JUNIOR, PEREIRA e PEREIRA FILHO, 2007). No segundo caso, os dados sobre o objeto de estudo, nos seus diversos casos, são relacionados e associados, oportunizando conclusões que podem ser generalizadas (PACHECO JUNIOR, PEREIRA e PEREIRA FILHO, 2007). O que caracteriza um caminho tipicamente indutivo, ou seja, do particular para o geral.

Em caso de haver conhecimento aceito acerca do objeto, sem restrições, as informações gerais não podem ser descuidadas, devendo ser aproveitadas em uma pesquisa. Pelo menos as que tenham relação direta com o objetivo do estudo (PACHECO JUNIOR, PEREIRA e PEREIRA FILHO, 2007; MARCONI e LAKATOS, 2011). Estas informações, disponíveis na literatura científica, facilitam não apenas o raciocínio lógico, na construção de novos conhecimentos, servindo como um referencial, mas evita que, se não forem negligenciadas, haja inconveniente contestação, tal como a acusação de plágio. Nesta ocorrência, o conhecimento é prévio na construção de novos e, através do raciocínio lógico, o mesmo deve ser avaliado em relação ao objeto de estudo, propiciando o que seja passível de generalização e aceito pela comunidade científica, possa ser confrontado com casos particulares. É a lógica tipicamente caracterizada como dedutiva, em que as informações prévias são confrontadas com o objeto de estudo, para não apenas verificar a aplicação, mas, também, possibilitar novas descobertas sobre o mesmo, evoluindo, assim, os conceitos (PACHECO JUNIOR, PEREIRA e PEREIRA FILHO, 2007; MARCONI e LAKATOS, 2011).

Por fim, para o conhecimento do objeto existente, porém, com significativas contestações, nota-se que o contraditório se manifesta em termos de raciocínio lógico, supondo-se que, uma pesquisa dessa natureza, seja conduzida buscando mostrar que o conhecimento, até então tido como verdadeiro, seja colocado à prova (PACHECO JUNIOR, PEREIRA e PEREIRA FILHO, 2007; MARCONI e LAKATOS, 2011). Tal caminho não quer dizer que seja tomado para negar o conhecimento prévio. Pelo contrário, supondo ser possível a sua evolução por confrontá-lo a casos particulares, pois o princípio de raciocínio é relativo às contingências, ou seja, situações e condições singulares que podem e devem propiciar diferentes resultados. Uma vez que neste raciocínio o conhecimento existente é base para um estudo particular, característica dedutiva, mas é colocado em julgamento a partir de suposições de não refletir a verdade e, assim, devendo ser negado, o caminho então é dito de hipotético-dedutivo (PACHECO JUNIOR, PEREIRA e PEREIRA FILHO, 2007; MARCONI e LAKATOS, 2011). As informações prévias para um dado objeto de estudo são negadas numa dada situação ou condição, sendo a pesquisa conduzida de modo a verificar a valia dessa negação.

Partindo-se dessas premissas sobre o raciocínio, que podem conduzir a resultados práticos em pesquisas científicas, quando se diz sobre o método, está se referindo ao modo de juízo lógico que leva ao conhecimento acerca do objeto de estudo (PACHECO JUNIOR, PEREIRA e PEREIRA FILHO, 2007). Deste modo, os métodos sob esta ótica podem ser classificados em (Quadro 3): 
Quadro 3 - Classificações da pesquisa científica quanto à lógica de raciocínio.

\begin{tabular}{|c|l|}
\hline Classificação & \multicolumn{1}{c|}{ Descrição } \\
\hline $\begin{array}{c}\text { Método } \\
\text { descritivo }\end{array}$ & $\begin{array}{l}\text { Processo de raciocínio em que se parte da premissa de que os fenômenos para } \\
\text { serem compreendidos em suas especificidades devem ser objetos de estudo, com a } \\
\text { subsequente descrição para possibilitar o conhecimento com relação aos elementos } \\
\text { envolvidos e respectivos relacionamentos. }\end{array}$ \\
\hline $\begin{array}{c}\text { Método } \\
\text { dedutivo }\end{array}$ & $\begin{array}{l}\text { Processo de raciocínio em que se parte de teorias e leis no predizer a ocorrência de } \\
\text { fenômenos específicos do objeto de estudo (conexão descendente do raciocínio), ou } \\
\text { seja, do geral para o particular e com o objetivo de explicar o conteúdo das premissas } \\
\text { da pesquisa. }\end{array}$ \\
\hline $\begin{array}{c}\text { Método } \\
\text { indutivo }\end{array}$ & $\begin{array}{l}\text { Processo de raciocínio em que se parte do conhecimento de fenômenos específicos } \\
\text { do objeto de estudo à formulação de teorias e leis (conexão ascendente do raciocínio), } \\
\text { ou seja, do particular para o geral e com o objetivo de generalizar as premissas de } \\
\text { pesquisa. }\end{array}$ \\
\hline $\begin{array}{c}\text { Método } \\
\text { hipotético- } \\
\text { dedutivo }\end{array}$ & $\begin{array}{l}\text { Processo de raciocínio em que se parte da premissa de que o conhecimento prévio } \\
\text { ("teorias e leis") não é universal e, desse modo, precisa ser testado nos fenômenos } \\
\text { específicos através da declaração de hipóteses e tentativas de expor a "falseabilidade } \\
\text { teórica" destas. }\end{array}$ \\
\hline
\end{tabular}

Fonte: Pacheco Junior, Pereira e Pereira Filho (2007, p. 55).

\subsection{As CARACTERIZAÇÕES DE PESQUISA}

As pesquisas podem ser consideradas sob três aspectos, quais sejam: sua natureza; seu tipo; e, a sua profundidade e amplitude. De acordo com a natureza, um estudo científico pode ser classificado por qualitativo ou quantitativo. Não é necessariamente o fato de apresentar mensurações de variáveis que torna uma pesquisa quantitativa. Pacheco Júnior, Pereira e Pereira Filho (2007) consideram como pesquisa quantitativa, por exemplo, quando a coleta e o tratamento de dados estatísticos apresentam um erro amostral de, no máximo, $5 \%$ para pesquisas de campo e 10\% para estudos de campo. Além disso, o nível de significância deve ser de 0,05\%. Entretanto, cabe ressaltar que é necessário conhecer critérios da área de estudo, para que os erros amostrais e a significância possam levar a caracterização correta da pesquisa.

Para classificar a pesquisa quanto ao tipo, assume-se que a mesma pode ser exploratória, descritiva ou conclusiva causal (Quadro 4). Cada tipo de pesquisa relaciona-se com diferentes tipos de procedimentos para a coleta de dados, porque os níveis de exigência se diferenciam conforme o objetivo de aprofundamento do pesquisador.

A caracterização da pesquisa, quanto a sua profundidade e amplitude, tem a ver com o grau de conhecimento que o pesquisador pretende obter sobre o fenômeno estudado. Essas características permitem classificar os estudos científicos em: pesquisas ou levantamentos de campo; estudos de campo; e, estudos de caso (Quadro 5). É possível que, em algumas das dimensões das classificações apresentadas, a pesquisa se apresente com características de mais de uma delas. No entanto, normalmente ocorre o predomínio de uma. 
Quadro 4 - Classificação da pesquisa científica quanto ao tipo.

\begin{tabular}{|c|l|}
\hline Classificação & \multicolumn{1}{c|}{ Descrição } \\
\hline Exploratória & $\begin{array}{l}\text { Os procedimentos adotados são para investigações em que o objeto de estudo apresenta } \\
\text { carência de conhecimento. É apropriada para os primeiros estágios de investigação, } \\
\text { pois não se tem clara definição dos procedimentos técnico-teóricos - o objetivo geral } \\
\text { apresenta-se impreciso ou é inexistente. Tal condição demanda ações simples que, } \\
\text { se o objetivo de pesquisa estiver aberto, podem ser trabalhosas para o alcance de } \\
\text { conhecimento, normalmente associando-se a técnicas, tais como: entrevistas abertas, } \\
\text { observações de campo sem planejamento, experimentos tipo tentativa e erro etc. }\end{array}$ \\
\hline Descritiva & $\begin{array}{l}\text { Os procedimentos adotados são para revelar as relações ente os elementos do objeto de } \\
\text { estudo e, neste aspecto, necessita um planejamento de investigação bem estruturado, } \\
\text { com uma clara definição das técnicas. É uma pesquisa que pode ser confundida com } \\
\text { a exploratória em caso de inexperiência do pesquisador, porém, diferencia-se desta } \\
\text { pelo fato de se dar maior importância à descrição do processo em que as variáveis se } \\
\text { relacionam. Neste caso, os parâmetros de causa(s) e efeito(s) são conhecidos, sendo } \\
\text { que o foco é o de descrever o fenômeno através de técnicas melhor estruturadas, tais } \\
\text { como: entrevistas semi-estruturadas, ou estruturadas, observações com planejamento, } \\
\text { experimentos semi-elaborados etc. }\end{array}$ \\
\hline Conclusiva \\
Causal & $\begin{array}{l}\text { Os procedimentos adotados neste tipo de investigação são bem elaborados, utilizando } \\
\text { técnicas consagradas para mostrar a causalidade entre variáveis. Em outros termos, } \\
\text { demonstra que o relacionamento entre as variáveis ocorre em razão de causa(s) } \\
\text { especificada(s), o que exige os objetivos bem definidos, de modo que os procedimentos } \\
\text { técnico-teóricos estejam bastante estruturados à obtenção de resposta para o problema } \\
\text { de pesquisa, bem como possibilitar a verificação das hipóteses. }\end{array}$ \\
\hline
\end{tabular}

Fonte: Pacheco Junior, Pereira e Pereira Filho (2007, p. 80-81).

Quadro 5 - Classificação da pesquisa científica quanto à amplitude e profundidade.

\begin{tabular}{|c|l|}
\hline Classificação & \multicolumn{1}{|c|}{ Descrição } \\
\hline Pesquisa de Campo & Grande amplitude e pouca profundidade. \\
\hline Estudo de Campo & Média amplitude na coleta de dados e média profundidade. \\
\hline Estudo de Caso & Pouca amplitude e grande profundidade. \\
\hline
\end{tabular}

Fonte: Pacheco Junior, Pereira e Pereira Filho (2007).

\subsection{A GESTÃO DE RISCOS AMBIENTAIS}

As origens do uso dos termos risco (risk) e perigo (hazard) remontam, segundo Marandola Jr. e Hogan (2004), aos estudos de geógrafos estadunidenses na década de 1920, envolvendo catástrofes naturais. Esses estudos foram denominados de natural hazards. Essas pesquisas se ampliaram por meio de estudos solicitados pelo governo dos Estados Unidos da América, no intuito de que fossem pesquisadas e propostas medidas para a resolução de problemas causados por inundações, em várias áreas daquele país. Assim, estudos envolvendo os perigos já eram realizados muito antes da proclamada crise ambiental que passou a ser evidenciada após a década de 1970. Em algumas literaturas científicas, estes termos são tidos como sinônimos, porém entende-se que o perigo está relacionado a uma ameaça potencial que pode causar consequências indesejáveis às pessoas ou aos bens, enquanto o risco está associado à probabilidade da ocorrência de um evento perigoso (MARANDOLA JR. e HOGAN, 2004; CASTRO, PEIXOTO E PIRES DO RIO, 2005; ARAÚJO JR, 2012). 
As sociedades sempre se depararam com a possibilidade de perigos, tendo em vista a exposição a eventos perigosos. Esses, inicialmente, eram associados aos desastres naturais, mas passaram a estar também ligados às atividades humanas e orientados por uma visão tecnocêntrica, devido às relações entre sociedade-natureza-tecnologia. Assim, os perigos, bem como os riscos associados a esses, podem ser classificados em três categorias: ambiental, ligado às incertezas sobre os eventos da natureza ou induzidos por atividades humanas; tecnológico, resultante das incertezas associadas às estruturas, processos e produtos tecnológicos; social, que ocorre como resultado das incertezas associadas às atividades humanas (MARANDOLA JR. e HOGAN, 2004; ESTEVES, 2011). A interação entre esses perigos e os riscos associados, gera outros de maior complexidade.

Nesse contexto, surge o conceito de vulnerabilidade, que está relacionado ao conjunto de fatores que colocam as pessoas, lugares, infraestruturas ou ecossistemas em condições de diminuição ou aumento à exposição aos perigos e aos riscos associados, aos quais podem estar expostos nas várias situações cotidianas (ACSELRAD, 2002; MARANDOLA JR. e HOGAN, 2006; ESTEVES, 2011). Embora a vulnerabilidade possa estar associada a determinados contextos geográficos e sociais, há situações em que os perigos são produzidos globalmente e ultrapassam fronteiras. Neste caso, a atuação de mecanismos locais pode funcionar como filtros na absorção de parte dos impactos ou danos, minimizando a forma que os mesmos chegarão às pessoas, lugares ou ecossistemas (MARANDOLA JR. e HOGAN, 2006). A vulnerabilidade tem sido a ideia força em vários domínios para lidar com os perigos, pois permite evidenciar ações, efetuar análises e propor soluções. Atualmente, é o conceito de vulnerabilidade que embasa várias políticas públicas.

Para se conhecer a vulnerabilidade é necessário realizar-se a avaliação de riscos, que envolve complexidade e interdependências entre diversos fatores, tais como: sociais, ambientais, tecnocientíficos, políticos, dentre outros. Para Marandola Jr. e Hogan (2006, p.38)

avaliar e gerir o risco, conhecendo as dinâmicas que produzem o perigo e os elementos que promovem a vulnerabilidade, é um esforço de tentar domar o indomável, de conhecer o intangível e de assegurar o incerto. Contudo, este reconhecimento não justifica uma paralisação diante do perigo; antes, reforça a necessidade de aprofundar os conhecimentos tanto dos mecanismos da geração de perigos quanto das possibilidades da sociedade, em geral, e das pessoas, em particular, de reagir e se proteger. Reconhecer este gap ajuda a colocar o conhecimento sobre vulnerabilidade no seu devido lugar: uma aproximação que tem limitações pela natureza do conhecimento científico, pelo dinamismo do espaço-tempo e pela incerteza inerente aos fenômenos estudados.

Neste contexto, surge a necessidade da gestão de riscos. Essa gestão precisa ser viabilizada por meio de políticas públicas que visem o bem comum. Para isso, Acselrad (2002) argumenta a necessidade de existir articulação entre degradação ambiental e injustiça social, pois é imperiosa a incorporação da multiplicidade social, relacionada aos riscos e ao raciocínio político que orienta a distribuição desigual dos mesmos. O autor defende que é possível a organização das sociedades para exigirem políticas públicas, capazes de minimizar as desigualdades geradas pelos riscos aos quais as mesmas estão sujeitas. A busca por políticas públicas que promovam o bem comum e, consequentemente, a justiça social, passa pela necessidade de o entendimento dos processos nos quais a sociedade se envolve. Por isso, identificar e estudar os problemas, envolvendo os riscos aos quais as sociedades vivenciam, é recorrente no contexto atual, em que a gestão do ambiente tornou-se foco de conflitos.

Por meio de políticas públicas, que levem ao reconhecimento da vulnerabilidade aos riscos, é que se pode efetuar a gestão de riscos, seja pública ou privada. Entretanto, Boeira (2003) lembra que no Brasil, bem como em outros países, os modelos de administração pública sofrem a influência da concepção que os guiam, a saber: a concepção do público como estatal ou do público visto como interesse público. São essas concepções, ligadas às visões de mundo dos indivíduos, juntamente com outros fatores, que acabam por definir o encaminhamento de gestão que os países, os municípios ou as empresas realizam. Essas visões de mundo são caracterizadas pelas formas, por meio das quais se percebe e se interpreta o mundo (tema em questão), para entendê-lo e transformá-lo, permeados por valores, crenças, princípios, bem como conceitos que se fazem presentes na realidade de cada indivíduo e coletividade, que estruturam os julgamentos e a tomada de decisões (TORRES, 2005).

Assim, as visões de mundo delineiam a maneira como as políticas ambientais vão tratar, por 
exemplo, a educação ambiental, o planejamento energético, o licenciamento ambiental, a avaliação de impactos e de riscos, dentre outras questões (SCHNEIDER, s/d). A gestão é um sistema composto por determinada estrutura organizacional (seja ela o Estado, cidade ou empresa), de planejamento e administração, na qual se realiza a organização, a execução e o controle de práticas, procedimentos, processos e recursos para implementar determinadas políticas (PFITSCHER et al., 2008).

Sob uma perspectiva sistêmica, a gestão deve considerar os elementos que são interdependentes e que pertencem: a) ao macroambiente; b) ao ambiente de tarefa; e, c) ao ambiente interno, sendo, no entendimento de Pacheco Junior, Pereira e Pereira Filho (2000, p.20),

[...] uma "arte" capaz de estabelecer, distribuir e integrar racionalmente os recursos para que se tenham requisitos mínimos [...] que permitam a estrutura organizacional a conduzir e animar ações visando atingir seus objetivos, com base em dados do macroambiente, ambiente de tarefa e ambiente interno.

Em relação aos perigos e os respectivos riscos associados, é papel da gestão procurar minimizar ou eliminar a vulnerabilidade nas pessoas, estruturas, lugares e/ou ecossistemas aos mesmos.

\section{PROCEDIMENTOS METODOLÓGICOS}

\section{I ENQUADRAMENTO METODOLóGICO}

Com base na referência adotada de Pacheco Júnior, Pereira e Pereira Filho (2007), o enquadramento metodológico, na condução da pesquisa apresentada neste artigo, é conforme o Quadro 6.

Quadro 6 - Enquadramento da pesquisa

\begin{tabular}{|c|l|}
\hline Classificação & \multicolumn{1}{|c|}{ Descrição } \\
\hline Pesquisa: Teórica & $\begin{array}{l}\text { Ênfase na discussão sobre a influência dos pressupostos metodológicos } \\
\text { na condução de pesquisa científica. }\end{array}$ \\
\hline $\begin{array}{c}\text { Base filosófica: } \\
\text { Estruturalista }\end{array}$ & $\begin{array}{l}\text { Buscou-se estabelecer relações entre os vários artigos selecionados para } \\
\text { identificar a forma como os pressupostos metodológicos se } \\
\text { interconectam. }\end{array}$ \\
\hline $\begin{array}{c}\text { Lógica de } \\
\text { raciocínio: } \\
\text { Dedutivo- } \\
\text { descritivo }\end{array}$ & $\begin{array}{l}\text { Parte do conhecimento explicitado em artigos internacionais, publicados } \\
\text { nos últimos dez anos, sobre gestão de riscos ambientais para obter dados } \\
\text { sobre a forma como as visões de mundo dos autores destes trabalhos } \\
\text { estruturaram suas pesquisas. Além disso, utiliza-se da lógica de } \\
\text { raciocínio descritiva para estabelecer as relações entre os artigos } \\
\text { analisados, evidenciando os elementos presentes e suas conexões. }\end{array}$ \\
\hline $\begin{array}{c}\text { Tipo: Descritivo } \\
\text { Natureza: }\end{array}$ & $\begin{array}{l}\text { O objetivo é revelar as relações entre os pressupostos metodológicos que } \\
\text { guiaram as pesquisas selecionadas. }\end{array}$ \\
\hline $\begin{array}{c}\text { Qualitativa } \\
\text { Amplitude e } \\
\text { Estudo de Caso }\end{array}$ & $\begin{array}{l}\text { Admite que a subjetividade dos autores deste estudo esteja presente nas } \\
\text { fases de análise e discussão dos artigos selecionados. }\end{array}$ \\
\hline $\begin{array}{l}\text { Foco na investigação dos pressupostos metodológicos de um portfólio, } \\
\text { versam sobre a gestão de riscos ambientais, disponibilizados na base de } \\
\text { dados Scopus. }\end{array}$ \\
\hline
\end{tabular}

Fonte: Autores, 2013. 


\subsection{Procedimentos para a seleção do portFólio analisado}

A sistemática utilizada na orientação dos procedimentos para a elaboração da presente pesquisa, da construção do referencial teórico, passando à seleção do portfólio de artigos, bem como as análises e a discussão sobre a influência dos pressupostos metodológicos, é apresentada na Figura 4.

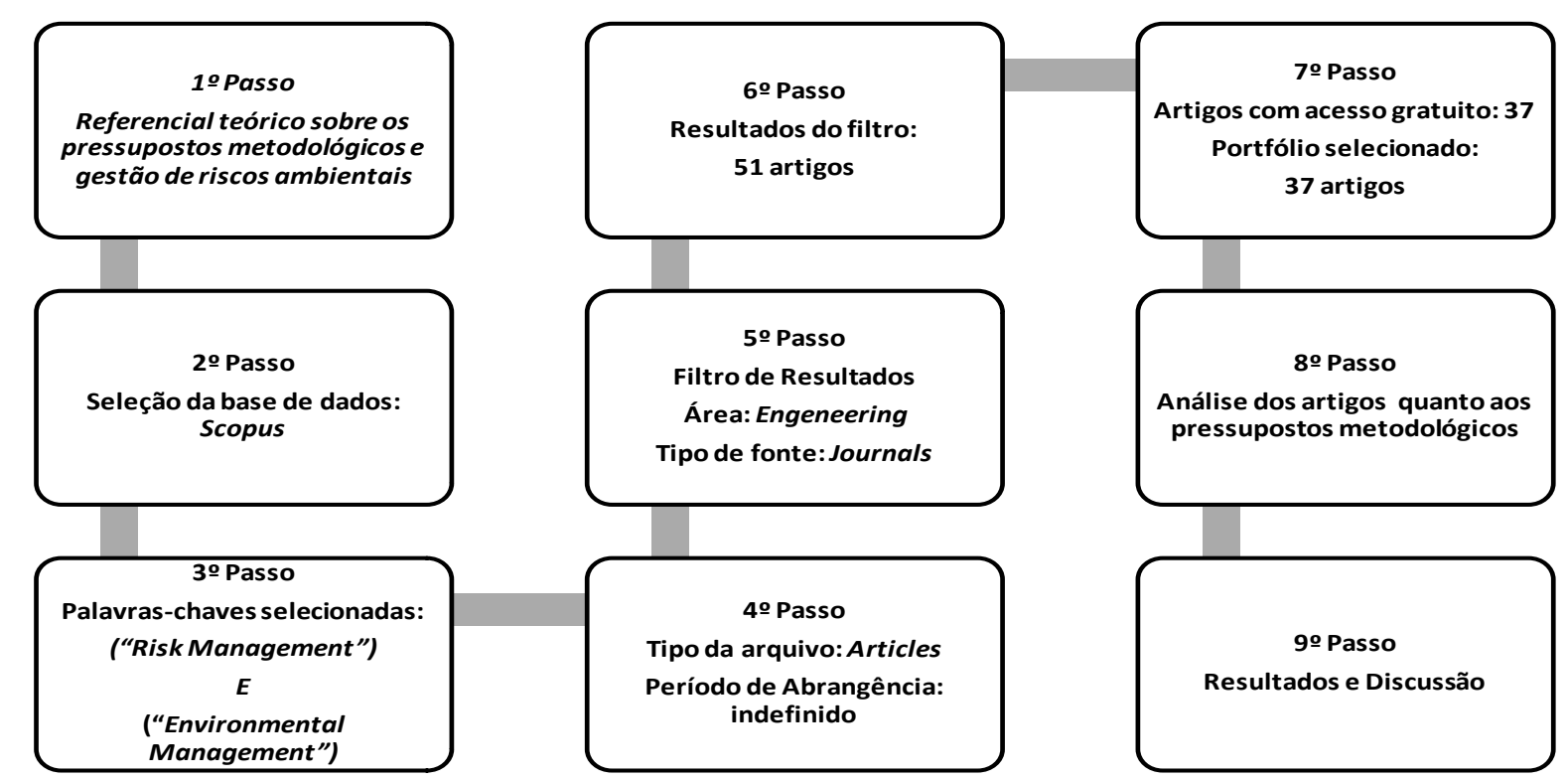

Figura 4 - Procedimentos para seleção do portfólio, análise e discussões de resultados.

Fonte: Autores, 2013.

\section{ANÁLISE}

A análise do portfólio pode ser conferida no Quadro 7 (APÊNDICE A). Sua realização deu-se da seguinte maneira:

Leitura de todos os artigos (Resumo e conteúdo); e,

Enquadramento de cada artigo, com base na percepção dos autores do presente trabalho, de acordo com os cinco pressupostos metodológicos arbitrados.

Base filosófica;

Método;

Tipologia;

Natureza; e,

Amplitude e profundidade.

\section{RESULTADOS E DISCUSSÕES}

A partir da análise realizada, no portfólio de artigos apresentados no Quadro 7 (APÊNDICE A), observou-se, inicialmente, com relação à base filosófica (primeira influenciadora dos pressupostos metodológicos na condução de pesquisas), a predominância de pesquisas sob a perspectiva do Estruturalismo (23 artigos); seguida do Positivismo (11 artigos); e, Dialética (3 artigos). A estratificação, em percentual, é apresentada na Figura 5.

A predominância dessa base pode estar associada à área de investigação (gestão de riscos ambientais), na qual os pesquisadores estão envolvidos em questões de alta complexidade, com a influência de uma miríade de fatores, cujos elementos buscam melhor compreender, para dar suporte às tomadas de decisões. Tal nível de complexidade, conforme evidenciado nos artigos do portfólio, sob uma abordagem sistêmica, pode ser devidamente caracterizada, por exemplo, pela hierarquia de sistemas, estando esses artigos localizados do $1^{\circ}$ ao $8^{\circ}$ nível (vide o trabalho de Boulding (1956), para maiores informações). 


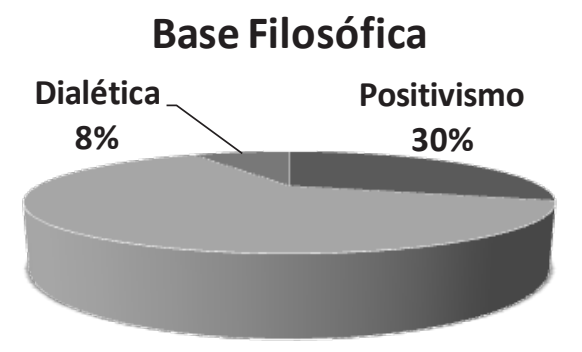

Estruturalismo

$62 \%$

Figura 5 - Estratificação dos artigos quanto às bases filosóficas.

Fonte: Autores, 2013.

\section{I Artigos Caracterizados pelo Estruturalismo}

Examinando-se os artigos, caracterizados pelo Estruturalismo (segundo a percepção dos autores deste artigo e a exposição sobre tal na seção 2.3.2), evidenciou-se que as lógicas de raciocínio utilizadas, apontam para o método dedutivo (4 artigos) e descritivo (1 artigo), bem como um misto entre os dois (18 artigos) (Figura 6).

\section{Estruturalismo}

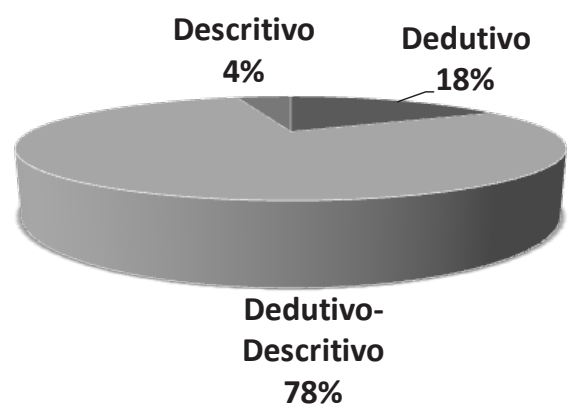

Figura 6 - Estratificação quanto ao Método.

Fonte: Autores, 2013.

A influência dessa base filosófica justifica-se, uma vez que

[...] o estruturalismo tem por escopo explicar as relações estruturais e funcionais entre os elementos que compõem um processo e, neste sentido, pode-se dizer que há a construção de um modelo - e modelo é sempre uma manifestação limitada da realidade - à explicação de um objeto de estudo. Logo, em se tratando de uma representação construída, a melhor forma de expressá-la é relatar sobre as relações existentes entre os elementos que compõem o objeto de estudo, o que remete a pensar-se que o método descritivo seja mais bem caracterizado dentro desta base filosófica (PACHECO JUNIOR, PEREIRA e PEREIRA FILHO, 2007, p.56).

Apesar de Pacheco Junior, Pereira e Pereira Filho (2007) não mencionarem o método dedutivo, é notória a sua influência e importância sobre as investigações desenvolvidas na atualidade, principalmente, na elaboração, seja do marco teórico, seja do quadro teórico, ou, simplesmente, do referencial teórico. Esses, por sua vez, geralmente são os responsáveis por prover a sustentação do arcabouço teórico, no desenvolvimento da investigação científica.

Mais adiante, evidenciou-se que esses pressupostos metodológicos exercem certa influência sobre a Tipologia, pois, em 21 artigos, encontraram-se indícios para que fossem caracterizados como Descritiva e, 2 artigos como Exploratória (Figura 7). Quanto ao pressuposto metodológico relacionado à Natureza, evidenciou-se, no Quadro 7 (APÊNDICE A), que todos os 23 artigos apontaram indícios para serem caracterizados como Qualitativa. É importante ressaltar que essa influência sobre 


\section{Estruturalismo}

\section{Exploratória}

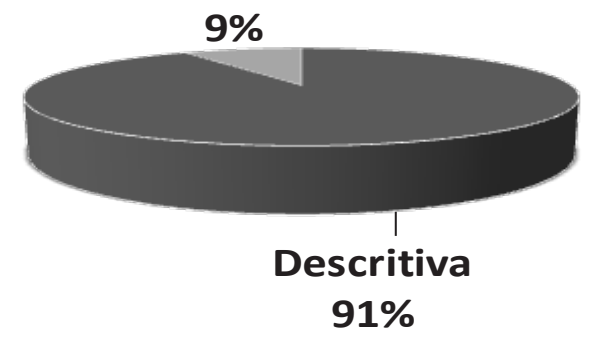

Figura 7 - Estratificação quanto à Tipologia.

Fonte: Autores, 2013.

a caracterização do pressuposto metodológico, relativo à Natureza da pesquisa, deva ser considerada como uma tendência condicionante.

Finalmente, com relação aos artigos orientados no Estruturalismo, evidenciou-se que 20 artigos apontaram indícios de se caracterizarem como Estudo de Caso; 2 artigos como Estudo de Campo; e, 1 artigo que não pôde ser devidamente enquadrado (Figura 8). Justifica-se o seu não enquadramento, por parte dos autores do presente artigo, por esse se tratar de uma proposta de cunho teórica, buscando aplicar princípios e uma estrutura retroalimentada, da gestão de riscos ambientais, para a restauração de instalações de caráter público, em contexto pós-ataque terrorista.

\section{Estruturalismo}

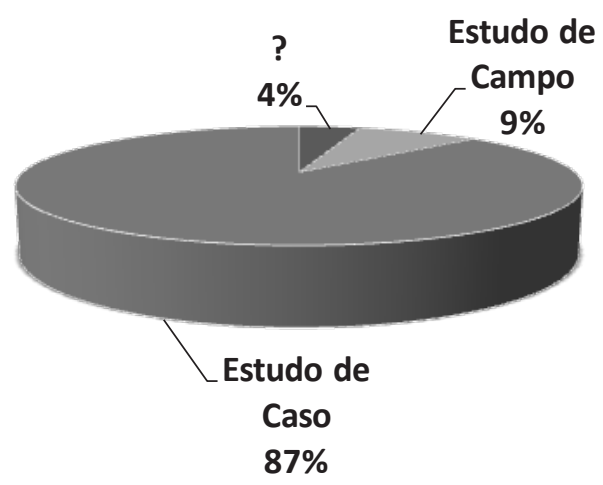

Figura 8 - Estratificação quanto à Amplitude e Profundidade.

Fonte: Autores, 2013.

\subsection{Artigos caracterizados pelo Positivismo}

Os artigos caracterizados pelo Positivismo (segundo a percepção dos autores deste artigo e a exposição sobre tal na seção 2.3.1) evidenciaram uma configuração singular, na influência dos pressupostos metodológicos. Com relação à lógica de raciocínio, houve predominância do método dedutivo (7 artigos); seguido de um misto do método dedutivo e descritivo (2 artigos); método dedutivo e indutivo (1 artigo); e, método hipotético-dedutivo (1 artigo) (Figura 9).

Apesar da predominância do método dedutivo, por motivos já explicitados nos parágrafos precedentes, a influência dessa base filosófica justifica-se, uma vez que

[...] o positivismo prioriza as estradas (causas) e as saídas (efeitos) para conhecer um processo (objeto de estudo) de modo a explicá-lo na lógica e racionalidade científica. Este procedimento pode ocorrer de modo ascendente, quando nenhum conhecimento há ou, se existe, sofre as restrições à plena aceitação devido à carência de informações, o que relaciona esta base filosófica ao método indutivo. Pode, ainda, ocorrer que a explicação ou justificação a partir das entradas 
e saídas ocorra de modo descendente, a partir de um alicerce de informações existentes sobre o mesmo, neste caso relacionando esta base filosófica também ao método dedutivo (PACHECO JUNIOR, PEREIRA e PEREIRA FILHO, 2007, p.56).

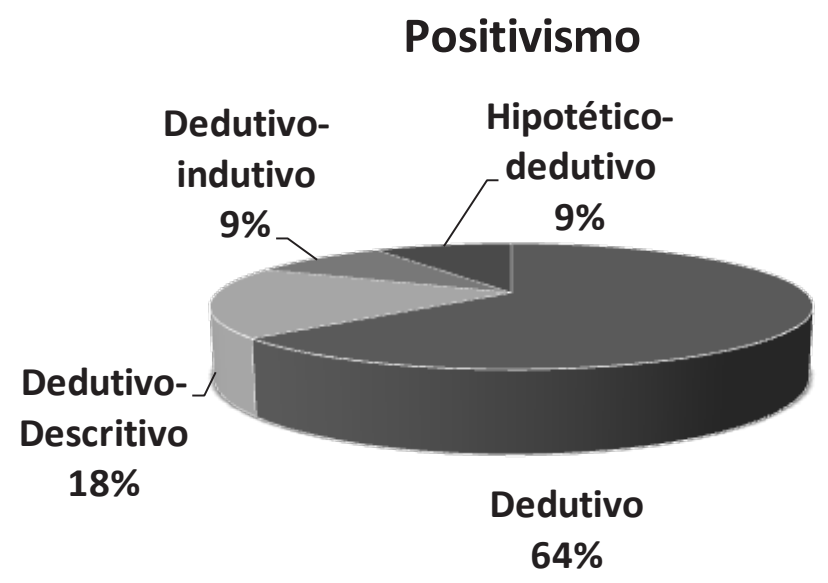

Figura 9 - Estratificação quanto ao Método.

Fonte: Autores, 2013

As variações evidenciadas do método dedutivo - integrado ao indutivo (sinalizando diferentes momentos de orientação do conhecimento, em uma mesma investigação) e ao descritivo (buscando melhor entendimento sobre as relações de causa e efeito entre as variáveis elencadas), refletem o grau de complexidade com o qual os pesquisadores se defrontaram na condução das investigações (que poderia ser caracterizada, por exemplo, pelo nível 7 e 8 da hierarquia proposta por Boulding (1956)). $\mathrm{O}$ método hipotético-dedutivo apareceu em um artigo, no qual seus autores buscaram investigar a conexão entre convicção e validação no julgamento de especialistas, em contexto de riscos associados no uso de determinada tecnologia.

Evidenciou-se que esses pressupostos metodológicos (sobretudo, pelo condicionamento à base filosófica, poder-se-ia intuir) exercem certa influência sobre a Tipologia, pois, em 10 artigos, encontraram-se indícios para que fossem caracterizados como Conclusiva Causal; e, 1 artigo como Exploratória (Figura 10). Essa influência condicionante torna-se evidente, uma vez que, o raciocínio que guia o pesquisador é uma relação de causa e efeito, centrada no objeto de estudo.

\section{Positivismo}

\section{Exploratória}

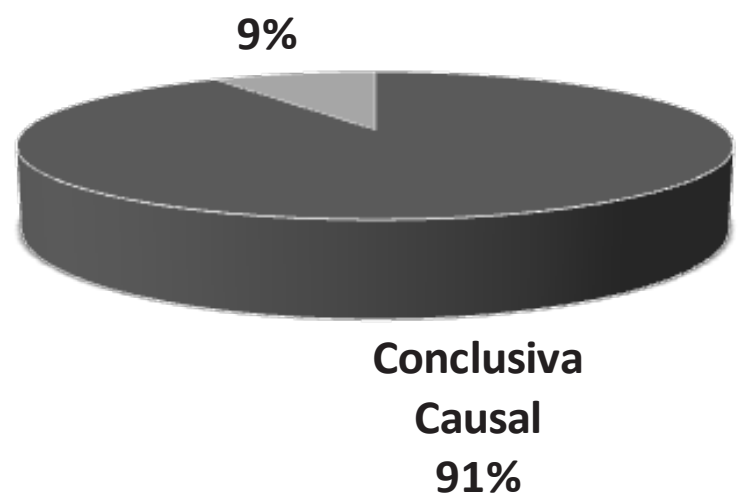

Figura 10 - Estratificação quanto à Tipologia.

Fonte: Autores, 2013. 
Quanto ao pressuposto metodológico relacionado à Natureza, evidenciou-se que, 10 artigos apontaram indícios para serem caracterizados como Qualitativa e 1 artigo como Quantitativa (Figura 11).

\section{Positivismo}

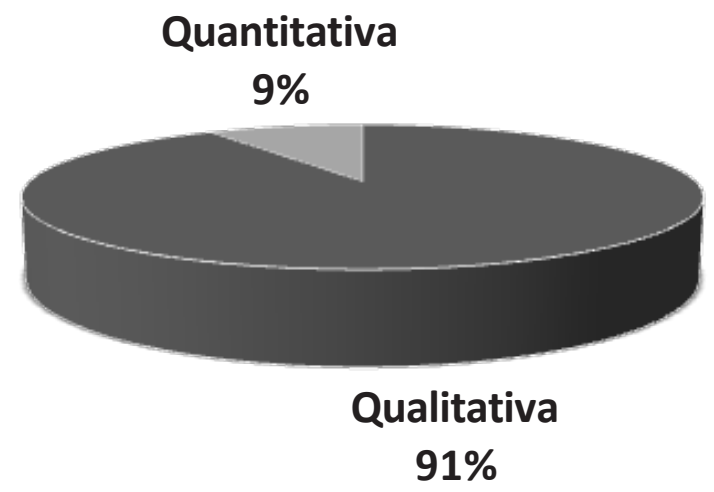

Figura 11 - Estratificação quanto à Natureza.

Fonte: Autores, 2013.

Finalmente, com relação aos artigos orientados no Positivismo, evidenciou-se que, 8 artigos apontaram indícios de caracterizarem como Estudo de Caso; 2 artigos como Estudo de Campo; e, 1 artigo como Pesquisa de Campo (Figura 12).

\section{Positivismo}

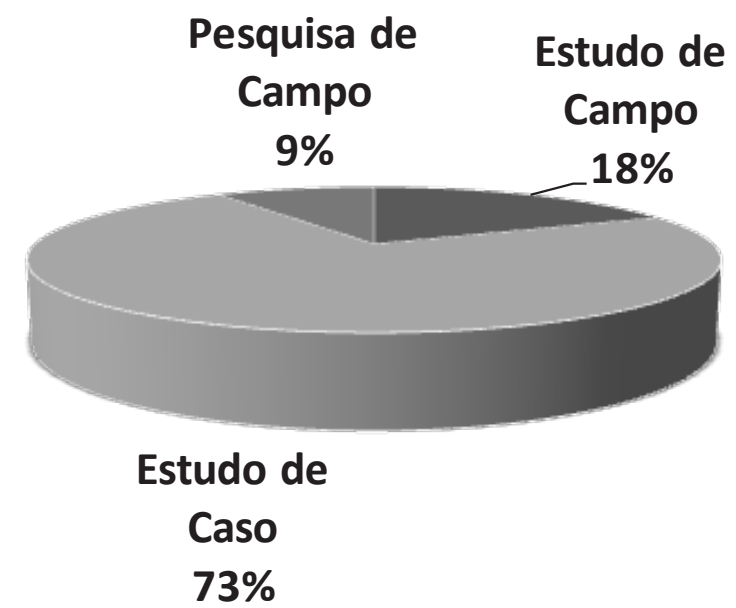

Figura 12 - Estratificação quanto à Amplitude e Profundidade.

Fonte: Autores, 2013.

\subsection{Artigos caracterizados pela Dialética}

Os 3 artigos que apontaram indícios de pertencerem à base Dialética (segundo a percepção dos autores deste artigo e a exposição sobre tal na seção 2.3.3), evidenciaram que a lógica de raciocínio utilizada convergiu, em todos eles, para o método dedutivo (Quadro 7 - Apêndice A). Essa evidência, a priori, diverge com a literatura consultada pelos autores deste trabalho, que 
[...] a dialética, por sua vez, visa evoluir o conhecimento existente através do contraditório daquilo que se pensa ser a explicação ou justificação de um dado objeto de estudo (a tese) e, assim, negando-o através de possíveis outras possibilidades e, confrontando as informações obtidas com o conhecimento anterior, buscar conclusões que possam melhor explicar ou justificar o objeto de estudo via eliminação de contradições. Esta concepção vai ao encontro exatamente do raciocínio do método hipotético-dedutivo, mostrando a sua relação com esta base filosófica (PACHECO JUNIOR, PEREIRA E PEREIRA FILHO, 2007, p.56).

Com relação aos demais pressupostos metodológicos, tanto a Tipologia quanto a Natureza, para os 3 artigos, apontaram evidências para caracterizarem como Descritiva e Qualitativa, respectivamente. Quanto à Profundidade e Amplitude, os artigos ID 12 e ID 27 (Quadro 7 - Apêndice A) por apresentaram discussões, nas quais seus autores buscaram defender seus posicionamentos no campo teórico, não permitiram a classificação referida neste artigo. Apenas o artigo ID 40, que foi caracterizado como um Estudo de Campo, pelas evidências apresentadas a partir de uma série histórica de publicações em periódicos arbitrados pelos seus autores.

\section{CONSIDERAÇÕES FINAIS}

A ciência não é um mistério a ser desvendado, nem muito menos uma atividade estática. Ela é uma concepção humana de aquisição dinâmica de conhecimento, pautada em procedimentos lógicos e racionais na investigação dos fenômenos. Esse aspecto, nem sempre entendido pela maioria dos pesquisadores iniciantes e, mesmo por aqueles que se mostram reticentes quanto à evolução do conhecimento, faz com que muito da produção científica seja realizada sem os critérios exigíveis de rigor científico e formalização, resultando em trabalhos de pouca expressividade e de dúbia aceitação nos centros de pesquisa. Para evitar tais situações indesejadas, é essencial conhecer, entender, aprender e apreender os mecanismos subjacentes que guiam a racionalidade na condução de uma pesquisa científica.

Embora se tenha recorrido à análise entre as partes que compõem essa racionalidade (na tentativa de expor as evidências de forma compreensível) para que fosse possível verificar a influência entre os pressupostos metodológicos, os autores desse artigo, sob uma perspectiva sistêmica, entendem que a coerência ou não das investigações deve ser observada no "todo", pois é a partir das relações estabelecidas entre os pressupostos metodológicos que essa característica emerge (e que consequentemente implicará na confiabilidade dos seus resultados) e, não se analisando, apenas, cada pressuposto individualmente e de forma isolada, como se cada um tivesse um fim em si mesmo.

Alerta-se para a compreensão da importância das três bases filosóficas na condução de pesquisas científicas. Cada uma delas propicia vantagens de uso em determinadas circunstâncias, de acordo com as pretensões do pesquisador. $\mathrm{Na}$ área de gestão de riscos, para o portfólio analisado, por exemplo, evidenciou-se, possivelmente pelo nível de complexidade dos fenômenos, a base do Estruturalismo predominantemente guiando as visões de mundo dos pesquisadores. Nesta base filosófica o foco de análise recai sobre os elementos contidos no processo, sejam eles, hardware, software, orgware ou humanware, para compreender suas inter-relações e melhor descrever o fenômeno investigado. No entanto, pode ocorrer que seja necessário identificar e testar relações de causa e efeito entre os elementos para verificar se as relações descritas se ratificam, ou seja, será preciso, em determinadas situações, trabalhar na base do Positivismo (influenciando os demais pressupostos metodológicos). E, para que o conhecimento existente sobre o fenômeno evolua, é inevitável o encontro de divergências, convergências, substituições ou complementações, ao longo da sua construção, configurando-se um trabalho caracterizado na base da Dialética, na qual se lançarão antíteses sobre as teses dos fenômenos conhecidos, para possibilitar obtenção de novas sínteses, fazendo avançar o conhecimento, em forma de espiral ascendente.

Trabalhar transitando em diferentes visões de mundo (bases filosóficas) é preciso; entretanto, o pesquisador deverá ter consciência sobre esse movimento (dinâmica) de ida e volta que dependerá do contexto a ser analisado, bem como de suas pretensões. Assim, considera-se esse discernimento, de transitar entre as bases, uma dificuldade (barreira) a ser superada pelos pesquisadores nos vários estágios de maturação em que estejam. O que só poderá ser transposto com muito esforço (trabalho), dedicação e reflexão. 


\section{REFERÊNCIAS}

ACSELRAD, H. Justiça Ambiental e Construção Social do Risco. Nepo/UNICAMP, 2002. Disponível em: http://www.abep.nepo.unicamp.br/docs/anais/pdf/2002/GT_MA_ST5_Acselrad_texto.pdf. Acesso em $20 / 05 / 2011$.

ARAÚJO Jr., A. C. R. Gestão de riscos naturais na Amazônia: ranços e avanços. In: Revista Geonorte, Edição Especial, v. 1, n. 4, pp. 676 - 686, 2012.

BEIERLE, T.C. The quality of stakeholder-based decisions. In: Risk Analysis, v. 22, n. 4, 2002, pp. 739-749.

BERTALANFFY, L. Von. Teoria Geral dos Sistemas. Vozes, 1975.

BOEIRA, S. L. Política \& gestão ambiental no Brasil: da Rio-92 ao estatuto da cidade. In: Alcance - UNIVALI, v. 10, n. 3, pp. $525-558,2003$.

BOULDING, K. General systems theory: the skeleton of science. Management Science, v. 2, n. 3, p.197-208, 1956.

BRUGGE, D.; VALLARINO, J.; ASCOLILLO, L.; OSGOOD, N.; STEINBACH, S.; SPENGLER, J. Comparison of multiple environmental factors for asthmatic children in public housing. In: Indoor air, v. 13, n. 1, pp. 18-27, 2003.

BRUHN, A; FRICK, K. Why it was so difficult to develop new methods to inspect work organization and psychosocial risks in Sweden. In: Safety Science, v. 49, n. 4, pp. 575-581, 2011.

BRYANT, D.L; ABKOWITZ, M.D. Development of a terrestrial chemical spill management system. In: Journal of hazardous materials, v. 147, n. 1-2, pp. 78-90, 2007.

CAREY, J.M.; BEILIN, R.; BOXSHALL, A.; BURGMAN, M.A.; FLANDER, L. Risk-based approaches to deal with uncertainty in a data-poor system: Stakeholder involvement in hazard identification for marine national parks and marine sanctuaries in Victoria, Australia. In: Risk Analysis, v. 27, n. 1, pp. 271-281, 2007.

CASTRO, C. M.; PEIXOTO, M. N. de O.; PIRES do RIO, G. A. Riscos ambientais e geografia: conceituações, cbordagens e escalas. In: Anuário do Instituto de Geociências - UFRJ, v. 28, n. 2, pp. 11-30, 2005.

EARLE, T. C.; SIEGRIST, M. On the relation between trust and fairness in environmental risk management. In: Risk Analysis, v. 28, n. 5, pp. 1395-1413, 2008.

EL-ZEIN, A.; NASRALLAH, R.; NUWAYHID, I.; KAI, L.; MAKHOUL, J. Why do neighbors have different environmental priorities? Analysis of environmental risk perception in a Beirut neighborhood. In: Risk Analysis, v. 26, n. 2, pp. 423-435, 2006.

ESTEVES, C. J. de O. Risco e vulnerabilidade socioambiental: aspectos conceituais. In: Cad. IPARDES, v. 1, n. 2, pp. 62-79, 2011.

FANGHUA, H.; GUANCHUN, C. 2010. A fuzzy multi-criteria group decision-making model based on weighted Borda scoring method for watershed ecological risk management: A case study of Three Gorges Reservoir area of China. In: Water Resources Management, v. 24, n. 10, pp. 2139-2165.

FEDRA, K.; WINKELBAUER, L. A hybrid expert system, GIS, and simulation modeling for environmental and technological risk management. In: Computer-Aided Civil and Infrastructure Engineering, v. 17, n. 2, pp. 131-146, 2002. 
GOULART, I. B. Psicologia da Educação. 13ª ed. Vozes: Rio de Janeiro, 2007.

HUNTER, J. C. O Monge e o executivo: uma história sobre a essência da liderança. 11. ed Rio de Janeiro: Sextante, 2004.

JAPIASSU, H. Como nasceu a ciência moderna: e as razões da filosofia. Rio de Janeiro: Imago, 2007.

LACOURSIERE, J. P. A risk management initiative implemented in Canada. In: Journal of hazardous materials, v. 130, n. 3 SPEC. ISS., pp. 311-320, 2006.

MARANDOLA JR., E; HOGAN, D. J. Natural hazards: o estudo geográfico dos riscos e perigos. In: Ambiente \& Sociedade, v. VII, n. 2, pp. 95-110, 2004.

. As dimensões da vulnerabilidade. In: São Paulo em Perspectiva, v. 20, n. 1, pp. 33-43, 2006.

MARCONI, M. A.; Lakatos, E.M. Metodologia Científica. 6. ed. São Paulo: Atlas, 2011.

MINAYO, M.C.S. O desafio do conhecimento: pesquisa qualitativa em saúde. 12ª ed. São Paulo: Hucitec, 2010.

MORIN, E. A introdução ao pensamento complexo. Trad. Eliane Lisboa. $4^{a}$ Edição, Porto Alegre: Sulinas, 2011.

NADAL, M.; KUMAR, V.; SCHUHMACHER, M.; Domingo, J. L. Applicability of a neuroprobabilistic integral risk index for the environmental management of polluted areas: A case study. In: Risk Analysis, v. 28, n. 2, pp. 271-286, 2008.

PACHECO JUNIOR, W.; PEREIRA, V. L. do V.; PEREIRA FILHO, H. do V. Gestão da Segurança e Higiene do Trabalho. São Paulo: Atlas, 2000.

Pesquisa Científica sem tropeços: Abordagem sistêmica. São Paulo: Atlas, 2007.

PALEOLOGOS, E. K. The lost value of groundwater and its influence on environmental decision making. In: Risk Analysis, v. 28, n. 4, pp. 939-950, 2008.

PFITSCHER, E. D.; VEGINI, D.; NUNES, J. P. de O.; ROSA, F. S. da. Contabilidade e auditoria ambiental como forma de gestão: um estudo de caso de um hospital. In: $18^{\circ}$ CONGRESSO BRASILEIRO DE CONTABILIDADE, 24 a 28 de agosto de 2008, Gramado-RS. Anais dos trabalhos científicos, 2008.

POLLARD, S. J. T.; KEMP, R. V.; CRAWFORD, M.; DUARTE-DAVIDSON, R.; IRWIN, J. G.; YEARSLEY, R. Characterizing environmental harm: Developments in an approach to strategic risk assessment and risk management. In: Risk Analysis, v. 24, n. 6, pp. 1551-1560, 2004.

QIN, X. S. Assessing environmental risks through fuzzy parameterized probabilistic analysis. In: Stochastic Environmental Research and Risk Assessment, v. 26, n. 1, pp. 43, 2012.

RICHARDSON, R. J. et al. Pesquisa Social: métodos e técnicas. São Paulo: Atlas, 1999.

ROCA, E.; GAMBOA, G.; TÀBARA, J. D. Assessing the multidimensionality of coastal erosion risks: Public participation and multicriteria analysis in a Mediterranean coastal system. In: Risk Analysis, v. 28, n. 2, pp. 399-412, 2008.

ROMERIO, F. Which paradigm for managing the risk of ionizing radiation? In: Risk Analysis, v. 22, n. 1, pp. 59-66, 2002. 
SCHNEIDER, E. Gestão ambiental municipal: preservação ambiental e o desenvolvimento sustentável. S/d. Disponível em http://www.files.bigeschi.webnode.com.br. Acesso em 20/12/2012.

TAN, Q.; HUANG, G.; CAI, Y. Robust planning of environmental management systems with adjustable conservativeness under compound uncertainty. In: Journal of Environmental Engineering, v. 138, n. 2, pp. 208-222, 2012.

THIRY-CHERQUES, H. R. O Primeiro Estruturalismo: Método de Pesquisa para as Ciências da Gestão. In: RAC, v. 10, n. 2, pp.137-156, 2006.

TORRES, J. J. M. Teoria da complexidade: uma nova visão de mundo para a estratégia. In: I EBEC - PUC/ PR - Curitiba, PR, Brasil, 11,12 e 13 de julho de 2005. Disponível em: http://www.facape.br/ruth/adm-filosofia/Texto_5_-_Teoria_da_Complexidade_e_Estrat.pdf.

VAN DER SLUIJS, J. P.; CRAYE, M.; FUNTOWICZ, S.; KLOPROGGE, P.; RAVETZ, J.; RISBEY, J. Combining quantitative and qualitative measures of uncertainty in model-based environmental assessment: The NUSAP system. In: Risk Analysis, v. 25, n. 2, pp. 481-492, 2005.

YUAN, R.; YANG, Y. S.; QIU, X.; MA, F. S. Environmental hazard analysis and effective remediation of highway seepage. In: Journal of hazardous materials, v. 142, n. 1-2, pp. 381-388, 2007

APÊNDICE A

Quadro 7 - Portfólio utilizado para investigar a influência dos pressupostos metodológicos.

\begin{tabular}{|c|c|c|c|c|c|c|}
\hline$I D$ & Artigo & $\begin{array}{c}\text { Base } \\
\text { Filosófica }\end{array}$ & Método & Tipologia & Natureza & $\begin{array}{l}\text { Amplitude e } \\
\text { Profundidade }\end{array}$ \\
\hline 01 & $\begin{array}{l}\text { ANTSIFEROVA, } \\
\text { I.V. Nanomaterials } \\
\text { and potential } \\
\text { environmental risks. } \\
\text { In: Russian Journal of } \\
\text { Non-Ferrous Metals, } \\
\text { v. 52, n. 1, 2011, pp. } \\
\text { 120-124. }\end{array}$ & Estruturalismo & Dedutivo & Descritiva & Qualitativa & Estudo de Caso \\
\hline 04 & $\begin{array}{l}\text { BEIERLE, T.C. The } \\
\text { quality of stakeholder- } \\
\text { based decisions. In: } \\
\text { Risk Analysis, v. 22, n. } \\
4,2002 \text {, pp. 739-749. }\end{array}$ & Positivismo & $\begin{array}{l}\text { Dedutivo- } \\
\text { Descritivo }\end{array}$ & $\begin{array}{l}\text { Conclusiva } \\
\text { Causal }\end{array}$ & Qualitativa & Pesquisa de Campo \\
\hline 05 & $\begin{array}{l}\text { BRUGGE, D.; } \\
\text { VALLARINO, J.; } \\
\text { ASCOLILLO, L.; } \\
\text { OSGOOD, N.; } \\
\text { STEINBACH, S.; } \\
\text { SPENGLER, J. } \\
\text { Comparison } \\
\text { of multiple } \\
\text { environmental factors } \\
\text { for asthmatic children } \\
\text { in public housing. In: } \\
\text { Indoor air, v. 13, n. 1, } \\
\text { 2003, pp. 18-27. }\end{array}$ & Positivismo & Dedutivo & $\begin{array}{l}\text { Conclusiva } \\
\text { Causal }\end{array}$ & Qualitativa & Estudo de Caso \\
\hline
\end{tabular}




\begin{tabular}{|c|c|c|c|c|c|c|}
\hline$I D$ & Artigo & $\begin{array}{c}\text { Base } \\
\text { Filosófica }\end{array}$ & Método & Tipologia & Natureza & $\begin{array}{l}\text { Amplitude e } \\
\text { Profundidade }\end{array}$ \\
\hline 06 & $\begin{array}{l}\text { BRUHN, A; FRICK, K. } \\
\text { Why it was so difficult } \\
\text { to develop new } \\
\text { methods to inspect } \\
\text { work organization and } \\
\text { psychosocial risks in } \\
\text { Sweden. In: Safety } \\
\text { Science, v. } 49, \text { n. } 4 \text {, } \\
\text { 2011, pp. 575-581. }\end{array}$ & Estruturalismo & $\begin{array}{l}\text { Dedutivo- } \\
\text { Descritivo }\end{array}$ & Descritiva & Qualitativa & Estudo de Caso \\
\hline 07 & $\begin{array}{l}\text { BRYANT, D.L; } \\
\text { ABKOWITZ, M.D. } \\
\text { Development of a } \\
\text { terrestrial chemical } \\
\text { spill management } \\
\text { system. In: Journal of } \\
\text { hazardous materials, } \\
\text { v. 147, n. 1-2, 2007, pp. } \\
\text { 78-90. }\end{array}$ & Estruturalismo & Dedutivo & Descritiva & Qualitativa & Estudo de Caso \\
\hline 08 & $\begin{array}{l}\text { BURGER, J.; POWERS, } \\
\text { C.; GREENBERG, M.; } \\
\text { GOCHFELD, M. The } \\
\text { role of risk and future } \\
\text { land use in cleanup } \\
\text { decisions at the } \\
\text { Department of Energy. } \\
\text { In: Risk Analysis, v. } \\
\text { 24, n. 6, 2004, pp. 1539- } \\
\text { 1549. }\end{array}$ & Estruturalismo & $\begin{array}{l}\text { Dedutivo- } \\
\text { Descritivo }\end{array}$ & Descritiva & Qualitativa & Estudo de Campo \\
\hline 09 & $\begin{array}{l}\text { CAREY, J.M.; BEILIN, } \\
\text { R.; BOXSHALL, A.; } \\
\text { BURGMAN, M.A.; } \\
\text { FLANDER, L. Risk- } \\
\text { based approaches to } \\
\text { deal with uncertainty } \\
\text { in a data-poor } \\
\text { system: Stakeholder } \\
\text { involvement in } \\
\text { hazard identification } \\
\text { for marine national } \\
\text { parks and marine } \\
\text { sanctuaries in Victoria, } \\
\text { Australia. In: Risk } \\
\text { Analysis, v. 27, n. 1, } \\
\text { 2007, pp. 271-281. }\end{array}$ & Estruturalismo & Dedutivo & Exploratória & Qualitativa & Estudo de Caso \\
\hline 10 & $\begin{array}{l}\text { CHRISTINI, G.; } \\
\text { FETSKO, M.; } \\
\text { HENDRICKSON, } \\
\text { C. Environmental } \\
\text { management } \\
\text { systems and ISO } \\
14001 \text { certification } \\
\text { for construction } \\
\text { firms. In: Journal } \\
\text { of Construction } \\
\text { Engineering and } \\
\text { Management, v. 130, n. } \\
\text { 3, 2004, pp. 330-336. }\end{array}$ & Estruturalismo & $\begin{array}{l}\text { Dedutivo- } \\
\text { Descritivo }\end{array}$ & Descritiva & Qualitativa & Estudo de Caso \\
\hline
\end{tabular}




\begin{tabular}{|c|c|c|c|c|c|c|}
\hline$I D$ & Artigo & $\begin{array}{c}\text { Base } \\
\text { Filosófica }\end{array}$ & Método & Tipologia & Natureza & $\begin{array}{c}\text { Amplitude e } \\
\text { Profundidade }\end{array}$ \\
\hline 11 & $\begin{array}{l}\text { CIOFFI, R.; } \\
\text { LAVORGNA, M.; } \\
\text { SANTORO, L. } \\
\text { Environmental } \\
\text { and technological } \\
\text { effectiveness of } \\
\text { a process for the } \\
\text { stabilization of a } \\
\text { galvanic sludge. In: } \\
\text { Journal of hazardous } \\
\text { materials, v. 89, n. 2-3, } \\
\text { 2002, pp. 165-175 }\end{array}$ & Positivismo & Dedutivo & $\begin{array}{c}\text { Conclusiva } \\
\text { Causal }\end{array}$ & Qualitativa & Estudo de Caso \\
\hline 12 & $\begin{array}{l}\text { COX Jr., L. A. What's } \\
\text { wrong with hazard- } \\
\text { ranking stems? An } \\
\text { expository note: } \\
\text { Perspectives. In: Risk } \\
\text { Analysis, v. 29, n. 7, } \\
\text { 2009, pp. } 940-948\end{array}$ & Dialética & Dedutivo & Descritiva & Qualitativa & $?$ \\
\hline 13 & $\begin{array}{l}\text { OLIVEIRA, P. T. S. } \\
\text { de; SOBRINHO, T.A.; } \\
\text { RODRIGUES, D. B. } \\
\text { B.; PANACHUKI, } \\
\text { E. Erosion Risk } \\
\text { Mapping Applied to } \\
\text { Environmental Zoning. } \\
\text { In: Water Resources } \\
\text { Management, v. 25, n. } \\
\text { 3, 2011, pp. 1021-1036. }\end{array}$ & Estruturalismo & $\begin{array}{l}\text { Dedutivo - } \\
\text { Descritivo }\end{array}$ & Descritiva & Qualitativa & Estudo de Caso \\
\hline 14 & $\begin{array}{l}\text { DOOLEY, J. J.; } \\
\text { TRABUCCHI, C.; } \\
\text { PATTON, L. Design } \\
\text { considerations for } \\
\text { financing a national } \\
\text { trust to advance } \\
\text { the deployment } \\
\text { of geologic CO2 } \\
\text { storage and motivate } \\
\text { best practices. In: } \\
\text { International Journal } \\
\text { of Greenhouse Gas } \\
\text { Control, v. 4, n. 2, 2010, } \\
\text { pp. 381-387. }\end{array}$ & Estruturalismo & Descritivo & Descritiva & Qualitativa & Estudo de Caso \\
\hline 15 & $\begin{array}{l}\text { EARLE, T. C.; } \\
\text { SIEGRIST, M. On } \\
\text { the relation between } \\
\text { trust and fairness in } \\
\text { environmental risk } \\
\text { management. In: Risk } \\
\text { Analysis, v. } 28, \text { n. } 5 \text {, } \\
\text { 2008, pp. 1395-1413. }\end{array}$ & Positivismo & $\begin{array}{l}\text { Dedutivo- } \\
\text { indutivo }\end{array}$ & $\begin{array}{l}\text { Conclusiva } \\
\text { Causal }\end{array}$ & Quantitativa & Estudo de Caso \\
\hline
\end{tabular}




\begin{tabular}{|c|c|c|c|c|c|c|}
\hline$I D$ & Artigo & $\begin{array}{c}\text { Base } \\
\text { Filosófica }\end{array}$ & Método & Tipologia & Natureza & $\begin{array}{l}\text { Amplitude e } \\
\text { Profundidade }\end{array}$ \\
\hline 16 & $\begin{array}{l}\text { EL-ZEIN, A.; } \\
\text { NASRALLAH, R.; } \\
\text { NUWAYHID, I.; KAI, } \\
\text { L.; MAKHOUL, J. } \\
\text { Why do neighbors } \\
\text { have different } \\
\text { environmental } \\
\text { priorities? Analysis } \\
\text { of environmental risk } \\
\text { perception in a Beirut } \\
\text { neighborhood. In: } \\
\text { Risk Analysis, v. 26, n. } \\
\text { 2, 2006, pp. 423-435. }\end{array}$ & Positivismo & $\begin{array}{l}\text { Dedutivo- } \\
\text { Descritivo }\end{array}$ & $\begin{array}{l}\text { Conclusiva } \\
\text { Causal }\end{array}$ & Qualitativa & Estudo de Campo \\
\hline 18 & $\begin{array}{l}\text { EOM, C. S. J.; PAEK, } \\
\text { J. H. Risk index } \\
\text { model for minimizing } \\
\text { environmental } \\
\text { disputes in } \\
\text { construction. } \\
\text { In: Journal of } \\
\text { Construction } \\
\text { Engineering and } \\
\text { Management, v. 135, n. } \\
\text { 1, 2009, pp. 34-41. }\end{array}$ & Estruturalismo & $\begin{array}{l}\text { Dedutivo- } \\
\text { Descritivo }\end{array}$ & Descritiva & Qualitativa & Estudo de Campo \\
\hline 20 & $\begin{array}{l}\text { FANG, Q.; ZHANG, } \\
\text { D.; WONG, L. N. Y. } \\
\text { Environmental risk } \\
\text { management for a } \\
\text { cross interchange } \\
\text { subway station } \\
\text { construction in China. } \\
\text { In: Tunnelling and } \\
\text { Underground Space } \\
\text { Technology, v. 26, n. 6, } \\
\text { 2011, pp. 750-763. }\end{array}$ & Estruturalismo & $\begin{array}{l}\text { Dedutivo- } \\
\text { Descritivo }\end{array}$ & Descritiva & Qualitativa & Estudo de Caso \\
\hline 21 & $\begin{array}{l}\text { FANGHUA, H.; } \\
\text { GUANCHUN, C. A } \\
\text { fuzzy multi-criteria } \\
\text { group decision- } \\
\text { making model based } \\
\text { on weighted Borda } \\
\text { scoring method for } \\
\text { watershed ecological } \\
\text { risk management: A } \\
\text { case study of Three } \\
\text { Gorges Reservoir } \\
\text { area of China. In: } \\
\text { Water Resources } \\
\text { Management, v. 24, n. } \\
\text { 10, 2010, pp. 2139-2165. }\end{array}$ & Estruturalismo & $\begin{array}{l}\text { Dedutivo- } \\
\text { Descritivo }\end{array}$ & Descritiva & Qualitativa & Estudo de Caso \\
\hline
\end{tabular}




\begin{tabular}{|c|c|c|c|c|c|c|}
\hline$I D$ & Artigo & $\begin{array}{c}\text { Base } \\
\text { Filosófica }\end{array}$ & Método & Tipologia & Natureza & $\begin{array}{l}\text { Amplitude e } \\
\text { Profundidade }\end{array}$ \\
\hline 22 & $\begin{array}{l}\text { FEDRA, K.; } \\
\text { WINKELBAUER, } \\
\text { L. A hybrid expert } \\
\text { system, GIS, and } \\
\text { simulation modeling } \\
\text { for environmental } \\
\text { and technological } \\
\text { risk management. In: } \\
\text { Computer-Aided Civil } \\
\text { and Infrastructure } \\
\text { Engineering, v. 17, n. 2, } \\
\text { 2002, pp. 131-146. }\end{array}$ & Estruturalismo & $\begin{array}{l}\text { Dedutivo- } \\
\text { Descritivo }\end{array}$ & Descritiva & Qualitativa & Estudo de Caso \\
\hline 24 & $\begin{array}{l}\text { FRENCH, S. P.; LEE, } \\
\text { D.; ANDERSON, } \\
\text { K. Estimating the } \\
\text { social and economic } \\
\text { consequences of } \\
\text { natural hazards: Fiscal } \\
\text { impact example. In: } \\
\text { Natural Hazards } \\
\text { Review, v. 11, n. 2, } \\
\text { 2010, pp. 49-57. }\end{array}$ & Estruturalismo & $\begin{array}{l}\text { Dedutivo- } \\
\text { Descritivo }\end{array}$ & Descritiva & Qualitativa & Estudo de Caso \\
\hline 25 & $\begin{array}{l}\text { GRIFFITHS, C. W.; } \\
\text { DOCKINS, C.; } \\
\text { OWENS, N.; SIMON, } \\
\text { N. B.; AXELRAD, D. } \\
\text { A. What to do at low } \\
\text { doses: A bounding } \\
\text { approach for economic } \\
\text { analysis. In: Risk } \\
\text { Analysis, v. 22, n. 4, } \\
\text { 2002, pp. 679-688. }\end{array}$ & Positivismo & Dedutivo & $\begin{array}{l}\text { Conclusiva } \\
\text { Causal }\end{array}$ & Qualitativa & Estudo de Caso \\
\hline 26 & $\begin{array}{l}\text { JO, H. Y.; MIN, S. H.; } \\
\text { LEE, T. Y.; AHN, H. } \\
\text { S.; LEE, S. H.; HONG, } \\
\text { J.K. Environmental } \\
\text { feasibility of using coal } \\
\text { ash as a fill material } \\
\text { to raise the ground } \\
\text { level. In: Journal of } \\
\text { hazardous materials, } \\
\text { v. 154, n. 1-3, 2008, pp. } \\
\text { 933-945. }\end{array}$ & Positivismo & Dedutivo & $\begin{array}{c}\text { Conclusiva } \\
\text { Causal }\end{array}$ & Qualitativa & Estudo de Caso \\
\hline 27 & $\begin{array}{l}\text { KIRCHSTEIGER, } \\
\text { C. Carbon capture } \\
\text { and storage- } \\
\text { desirability from a risk } \\
\text { management point } \\
\text { of view. In: Safety } \\
\text { Science, v. } 46, \text { n. } 7 \text {, } \\
\text { 2008, pp. } 1149-1154 \text {. }\end{array}$ & Dialético & Dedutivo & Descritiva & Qualitativa & $?$ \\
\hline
\end{tabular}




\begin{tabular}{|c|c|c|c|c|c|c|}
\hline$I D$ & Artigo & $\begin{array}{c}\text { Base } \\
\text { Filosófica }\end{array}$ & Método & Tipologia & Natureza & $\begin{array}{l}\text { Amplitude e } \\
\text { Profundidade }\end{array}$ \\
\hline 29 & $\begin{array}{l}\text { LACOURSIERE, J. P. } \\
\text { A risk management } \\
\text { initiative implemented } \\
\text { in Canada. In: } \\
\text { Journal of hazardous } \\
\text { materials, v. 130, n. } 3 \\
\text { SPEC. ISS., 2006, pp. } \\
\text { 311-320. }\end{array}$ & Estruturalismo & $\begin{array}{l}\text { Dedutivo- } \\
\text { Descritivo }\end{array}$ & Descritiva & Qualitativa & Estudo de caso \\
\hline 31 & $\begin{array}{l}\text { LINDELL, M. K.; } \\
\text { PRATER, C. S. } \\
\text { Tsunami preparedness } \\
\text { on the Oregon and } \\
\text { Washington coast: } \\
\text { Recommendations for } \\
\text { research. In: Natural } \\
\text { Hazards Review, v. 11, } \\
\text { n. 2, 2010, pp. 69-81. }\end{array}$ & Estruturalismo & $\begin{array}{l}\text { Dedutivo- } \\
\text { Descritivo }\end{array}$ & Exploratória & Qualitativa & Estudo de Caso \\
\hline 33 & $\begin{array}{l}\text { NADAL, M.; KUMAR, } \\
\text { V.; SCHUHMACHER, } \\
\text { M.; DOMINGO, J. } \\
\text { L. Applicability of a } \\
\text { neuroprobabilistic } \\
\text { integral risk index for } \\
\text { the environmental } \\
\text { management of } \\
\text { polluted areas: A } \\
\text { case study. In: Risk } \\
\text { Analysis, v. 28, n. 2, } \\
\text { 2008, pp. 271-286. }\end{array}$ & Estruturalismo & Dedutivo & Descritiva & Qualitativa & Estudo de Caso \\
\hline 35 & $\begin{array}{l}\text { PALEOLOGOS, E. } \\
\text { K. The lost value } \\
\text { of groundwater } \\
\text { and its influence } \\
\text { on environmental } \\
\text { decision making. In: } \\
\text { Risk Analysis, v. 28, n. } \\
\text { 4, 2008, pp. 939-950. }\end{array}$ & Positivismo & Dedutivo & $\begin{array}{l}\text { Conclusiva } \\
\text { Causal }\end{array}$ & Qualitativa & Estudo de Caso \\
\hline 37 & $\begin{array}{l}\text { POLLARD, S. J. } \\
\text { T.; KEMP, R. V.; } \\
\text { CRAWFORD, M.; } \\
\text { DUARTE-DAVIDSON, } \\
\text { R.; IRWIN, J. G.; } \\
\text { YEARSLEY, R. } \\
\text { Characterizing } \\
\text { environmental harm: } \\
\text { Developments in an } \\
\text { approach to strategic } \\
\text { risk assessment and } \\
\text { risk management. In: } \\
\text { Risk Analysis, v. 24, n. } \\
\text { 6, 2004, pp. 1551-1560. }\end{array}$ & Estruturalismo & $\begin{array}{l}\text { Dedutivo- } \\
\text { Descritivo }\end{array}$ & Descritiva & Qualitativa & Estudo de Caso \\
\hline
\end{tabular}




\begin{tabular}{|c|c|c|c|c|c|c|}
\hline$I D$ & Artigo & $\begin{array}{c}\text { Base } \\
\text { Filosófica }\end{array}$ & Método & Tipologia & Natureza & $\begin{array}{l}\text { Amplitude e } \\
\text { Profundidade }\end{array}$ \\
\hline 38 & $\begin{array}{l}\text { QIN, X. S. Assessing } \\
\text { environmental } \\
\text { risks through fuzzy } \\
\text { parameterized } \\
\text { probabilistic analysis. } \\
\text { In: Stochastic } \\
\text { Environmental } \\
\text { Research and Risk } \\
\text { Assessment, v. 26, n. 1, } \\
\text { 2012, pp. } 43 .\end{array}$ & Estruturalismo & $\begin{array}{l}\text { Dedutivo- } \\
\text { Descritivo }\end{array}$ & Descritiva & Qualitativa & Estudo de Caso \\
\hline 39 & $\begin{array}{l}\text { ROCA, E.; GAMBOA, } \\
\text { G.; TÀBARA, J. } \\
\text { D. Assessing the } \\
\text { multidimensionality of } \\
\text { coastal erosion risks: } \\
\text { Public participation } \\
\text { and multicriteria } \\
\text { analysis in a } \\
\text { Mediterranean coastal } \\
\text { system. In: Risk } \\
\text { Analysis, v. 28, n. 2, } \\
\text { 2008, pp. 399-412. }\end{array}$ & Estruturalismo & $\begin{array}{l}\text { Dedutivo- } \\
\text { Descritivo }\end{array}$ & Descritiva & Qualitativa & Estudo de Caso \\
\hline 40 & $\begin{array}{l}\text { ROMERIO, F. } \\
\text { Which paradigm for } \\
\text { managing the risk of } \\
\text { ionizing radiation? In: } \\
\text { Risk Analysis, v. 22, n. } \\
\text { 1, 2002, pp. 59-66. }\end{array}$ & Dialético & Dedutivo & Descritiva & Qualitativa & Estudo de Campo \\
\hline 42 & $\begin{array}{l}\text { SCHOLZ, R. W.; } \\
\text { HANSMANN, R. } \\
\text { Combining experts } \\
\text { risk judgments } \\
\text { on technology } \\
\text { performance of } \\
\text { phytoremediation: } \\
\text { Self-confidence ratings, } \\
\text { averaging procedures, } \\
\text { and formative } \\
\text { consensus building. In: } \\
\text { Risk Analysis, v. } 27, \mathrm{n} . \\
\text { 1, 2007, pp. 225-240. }\end{array}$ & Positivismo & $\begin{array}{c}\text { Hipotético- } \\
\text { dedutivo }\end{array}$ & $\begin{array}{l}\text { Conclusiva } \\
\text { Causal }\end{array}$ & Qualitativa & Estudo de Caso \\
\hline 44 & $\begin{array}{l}\text { TAN, Q.; HUANG, } \\
\text { G.; CAI, Y. Robust } \\
\text { planning of } \\
\text { environmental } \\
\text { management systems } \\
\text { with adjustable } \\
\text { conservativeness } \\
\text { under compound } \\
\text { uncertainty. } \\
\text { In: Journal of } \\
\text { Environmental } \\
\text { Engineering, v. 138, n. } \\
\text { 2, 2012, pp. 208-222. }\end{array}$ & Estruturalismo & $\begin{array}{l}\text { Dedutivo- } \\
\text { Descritivo }\end{array}$ & Descritiva & Qualitativa & Estudo de Caso \\
\hline
\end{tabular}




\begin{tabular}{|c|c|c|c|c|c|c|}
\hline$I D$ & Artigo & $\begin{array}{c}\text { Base } \\
\text { Filosófica }\end{array}$ & Método & Tipologia & Natureza & $\begin{array}{l}\text { Amplitude e } \\
\text { Profundidade }\end{array}$ \\
\hline 45 & $\begin{array}{l}\text { VAN DER SLUIJS, } \\
\text { J. P.; CRAYE, M.; } \\
\text { FUNTOWICZ, S.; } \\
\text { KLOPROGGE, P.; } \\
\text { RAVETZ, J.; RISBEY, } \\
\text { J. Combining } \\
\text { quantitative and } \\
\text { qualitative measures } \\
\text { of uncertainty } \\
\text { in model-based } \\
\text { environmental } \\
\text { assessment: The } \\
\text { NUSAP system. In: } \\
\text { Risk Analysis, v. 25, n. } \\
\text { 2, 2005, pp. 481-492. }\end{array}$ & Estruturalismo & $\begin{array}{l}\text { Dedutivo- } \\
\text { Descritivo }\end{array}$ & Descritiva & Qualitativa & Estudo de Caso \\
\hline 46 & $\begin{array}{l}\text { WHICKER, J. J.; } \\
\text { JANECKY, D. } \\
\text { R.; DOERR, T. } \\
\text { B. Adaptive } \\
\text { management: } \\
\text { A paradigm for } \\
\text { remediation of public } \\
\text { facilities following } \\
\text { a terrorist attack. In: } \\
\text { Risk Analysis, v. 28, n. } \\
\text { 5, 2008, pp. 1445-1456. }\end{array}$ & Estruturalismo & $\begin{array}{l}\text { Dedutivo- } \\
\text { Descritivo }\end{array}$ & Descritiva & Qualitativa & $?$ \\
\hline 47 & $\begin{array}{l}\text { WILLIS, H. H.; DEKAY, } \\
\text { M. L.; FISCHHOFF, } \\
\text { B.; MORGAN, } \\
\text { M. G. Aggregate, } \\
\text { disaggregate, and } \\
\text { hybrid analyses } \\
\text { of ecological risk } \\
\text { perceptions. In: Risk } \\
\text { Analysis, v. 25, n. 2, } \\
\text { 2005, pp. 405-428. }\end{array}$ & Positivismo & Dedutivo & Exploratória & Qualitativa & Estudo de Caso \\
\hline 49 & $\begin{array}{l}\text { YIN, H.; PFAFF, A.; } \\
\text { KUNREUTHER, H. } \\
\text { Can Environmental } \\
\text { Insurance Succeed } \\
\text { Where Other } \\
\text { Strategies Fail? The } \\
\text { Case of Underground } \\
\text { Storage Tanks. In: Risk } \\
\text { Analysis, v. 31, n. 1, } \\
\text { 2011, pp. 12-24. }\end{array}$ & Positivismo & Dedutivo & $\begin{array}{l}\text { Conclusiva } \\
\text { Causal }\end{array}$ & Qualitativa & Estudo de Campo \\
\hline 50 & $\begin{array}{l}\text { YUAN, R.; YANG, Y. } \\
\text { S.; QIU, X.; MA, F. S. } \\
\text { Environmental hazard } \\
\text { analysis and effective } \\
\text { remediation of } \\
\text { highway seepage. In: } \\
\text { Journal of hazardous } \\
\text { materials, v. 142, n. } \\
\text { 1-2, 2007, pp. 381-388. }\end{array}$ & Estruturalismo & $\begin{array}{l}\text { Dedutivo- } \\
\text { Descritivo }\end{array}$ & Descritiva & Qualitativa & Estudo de Caso \\
\hline
\end{tabular}

Fonte: Autores, 2013. 